\title{
How Ethical Behavior of Firms is Influenced by the Legal and Political Environments: A Bayesian Causal Map Analysis Based on Stages of Development
}

\author{
Ahmet Ekici • Sule Onsel
}

Received: 26 July 2011 / Accepted: 25 June 2012/Published online: 12 July 2012

(C) Springer Science+Business Media B.V. 2012

\begin{abstract}
Even though potential impacts of political and legal environments of business on ethical behavior of firms (EBOF) have been conceptually recognized, not much evidence (i.e., empirical work) has been produced to clarify their role. In this paper, using Bayesian causal maps (BCMs) methodology, relationships between legal and political environments of business and EBOF are investigated. The unique design of our study allows us to analyze these relationships based on the stages of development in 92 countries around the world. The EBOF models structured through BCMs are used to explain how EBOF in a given country group are shaped by how managers perceive political, legislative, and protective environments of business in these countries. The results suggest that irregular payments and bribes are the most influential factors affecting managers' perceptions of business ethics in relatively more advanced economies, whereas intellectual property protection is the most influential factor affecting managers' perceptions of business ethics in less-advanced economies. The results also suggest that regardless of where the business is conducted in the world, judicial independence is the driving force behind managers' perceptions of business ethics. In addition, the results of this study provide further support for scholars who argue that business ethics is likely to vary among countries based on their socio-economic factors. In addition to its managerial
\end{abstract}

\footnotetext{
A. Ekici ( $₫)$

Faculty of Business Administration, Bilkent University, 06800 Bilkent, Ankara, Turkey

e-mail: ekici@bilkent.edu.tr

S. Onsel

Dogus University, Engineering Faculty, Acibadem, Istanbul, Turkey

e-mail: sonsel@dogus.edu.tr
}

implications, the study provides directions for policy makers to improve the ethical conduct of businesses in their respective countries.

Keywords Bayesian causal map - Ethical behavior of firms · Judicial independence $\cdot$ Bribery $\cdot$ Intellectual property protection $\cdot$ Country development stage

$\begin{array}{ll}\text { Abbreviations } \\ \text { WEF } & \text { World Economic Forum } \\ \text { BCM } & \text { Bayesian causal map } \\ \text { EOS } & \text { Executive Opinion Survey } \\ \text { GCI } & \text { Global Competitiveness Index } \\ \text { EBOF } & \text { Ethical behavior of firms } \\ \text { IPP } & \text { Intellectual property protection } \\ \text { IPAB } & \text { Irregular payments and bribes } \\ \text { JI } & \text { Judicial independence } \\ \text { FDGO } & \text { Favoritism in decisions of government officials } \\ \text { TGP } & \text { Transparency of government policymaking } \\ \text { SARS } & \text { Strength of auditing and reporting standards } \\ \text { ECB } & \text { Efficacy of corporate boards } \\ \text { SIP } & \text { Strength of investor protection } \\ \text { IPR } & \text { Intellectual property rights }\end{array}$

\section{Introduction}

Ethical issues are a major concern for businesses because they have significant impacts on various stakeholders including the company, customers, employees, shareholders, and society in general. Considering the significance of this impact, a great deal of scholarly work (both theoretical and empirical) has been devoted to advance our understanding of the factors affecting ethical behavior of firms (EBOF). 
Especially since the 1980s, scholars from various areas of business have introduced models of ethical (or unethical) decision making (e.g., Bommer et al. 1987; Ferrell and Gresham 1985; Hunt and Vitell 1986, 1993; Jones 1991; Stead et al. 1990; Trevino 1986; Vitell 1986). These models identified various factors influencing EBOF. A review of these models suggest that factors influencing ethical behavior can be grouped into individual characteristics of the decision maker, organizational (companyspecific) factors, situational and contextual factors, social and cultural environment, business/industry environment, and governmental and legal environments.

There is a significant amount of research within marketing, organization studies, and international management that empirically demonstrates the impacts of most of these factors on business ethics. As can be clearly seen in a number of comprehensive review papers such as Ford and Richardson (1994), Loe et al. (2000), Nill and Schibrowsky (2007), O'Fallan and Butterfield (2005), and Tsalikis and Fritzsche (1989), the role that individual, organizational, and contextual factors play in the ethical decisions made in organizations has been well established. In addition, scholars of international business ethics in particular have demonstrated the role of certain social and cultural factors (including family and religion) on ethical decision making in organizations (e.g., Jing and Graham 2008; Pitta et al. 1999; Srnka 2004; Stajkovic and Luthans 1997). However, even though conceptually recognized by the ethical decision-making models mentioned above, relatively less empirical attention has been paid to the impacts of legal, political, and professional/business environments on the EBOF.

The purpose of this study is to advance our understanding of how certain institutional factors related to political and legal environments of business affect EBOF. In addition to personal, organizational (company-specific), and social and cultural factors, business ethics is also shaped by the legal, political, and business institutions of a society (e.g., Bommer et al. 1987; Hunt and Vitell 1986, 1993; Stead et al. 1990). As noted earlier, most of the empirical work to date has dealt with either micro (individual and/or company) level or uncontrollable macro level issues (such as culture) of business ethics. The role that legal, political, and business institutions play in the ethical decisions businesses make has received relatively less attention. We believe that understanding the impacts of the institutions on the EBOF is very important. Once the relationships between political and legal institutional factors and business ethics are established, by using appropriate policy interventions, the performances of these institutions can be improved. Consequently, the ethical performances of businesses can also be improved. This, in turn, leads to a well-served and competitive economy. As noted also in the WEF report (Sala-i-Martin et al. 2011), existence of strong ethical practices for a firm in their dealings with the government, other firms, and the public is the main component of a competitive economy. It is obvious that concerns about the protection of property rights, ethics and corruption, undue influence, and government inefficiencies lead to an institutional environment that does not support a well-served economy.

More specifically, using the World Economic Forum (WEF) data and through the Bayesian causal map (BCM) methodology, we study how EBOF in a given country group are shaped by how managers perceive the political, legislative, and protective environments of business in these countries. The data that was used to compute the Global Competitiveness Index (GCI) were collected from 13,000 executives in 139 countries. The unique design of our study allows us to compare these relationships based on the country classification (stages of development) indentified by WEF. This way, we are able to demonstrate how issues related to legal and political environments of business are linked to EBOF operating in countries with different stages of development.

In their analysis of global competitiveness, by using the well-established economic theory of stages of development, WEF identifies three distinct groups of economies: factor driven, efficiency driven, and innovation driven. More specifically, the Global Competitiveness Report (Sala-i-Martin et al. 2010) states that:

In the first stage, the economy is factor driven and countries compete based on their factor endowments: primarily unskilled labor and natural resources. Countries then move into the efficiency-driven stage of development, when they must begin to develop more efficient production processes and increase product quality. Finally, countries move into the innovation-driven stage, where companies must compete by producing new and different goods using the most sophisticated production processes and through innovation (p. 9).

The rest of the paper is structured as follows: First, we review existing conceptualizations and empirical work that deal with factors affecting EBOF. Then we outline the research methodology, including the rationale behind the selection of the BCM method and the procedure followed for selection of institutional factors used in the study. The findings section discusses how the BCM models are shaped for each of the three country groups. The paper concludes by discussing its conceptual and methodological contributions, managerial and public policy implications, and future research areas. 


\section{Factors Affecting Ethical Behavior}

Scholars from diverse disciplines in business offered conceptual models that delineate various factors affecting business ethics and ethical decision making. Some of these models focus on a narrow range of factors such as individual and situational variables (e.g., Trevino 1986) or the characteristics of the ethical issue itself (e.g., Jones 1991). In this section, we briefly review models that are recognized as more comprehensive in nature (Wyld and Jones 1997).

The General Theory of Marketing Ethics (Hunt and Vitell 1986, 1993; one of the most cited and tested models in the business ethics literature) posits that ethical behaviors of managers are influenced by a host of environmental, situational, and contextual factors such as cultural environment (e.g., religion, legal system, and political system), general business environment (professional, industry, and organizational) as well as personal characteristics of the decision maker. The model also argues that how decision makers perceive the ethical problem, available alternatives, and the probability of resulting consequences shape their ethical behavior.

Various components of this theory have been tested since its introduction. Most empirical work has focused on the personal characteristics of the decision maker, with relatively less attention being paid to the impact of "general business" and "cultural and political environment" components. For example, Singhapakdi and Vitell (1990, 1991) studied the impact of personal (background) characteristics such as Machiavellianism and locus of control on ethical decision making. Hunt and Vasquez-Parraga (1993) study found gender as a personal characteristic that shapes managers' ethical decisions. Burns and Kiecker (1995), Donoho et al. (1999), Mayo and Marks (1990), Menguc (1998), and Vitell et al. (2001) studied the impact of deontological versus teleological orientations of the decision maker.

Bommer et al. (1987) proposed a normative ethical decision model and argued that individual attributes of the decision maker, the work environment, professional environment, personal environment, social environment, and government/legal environment affect ethical/unethical behavior. Over the last 25 years, this model has been an inspiration to more than 300 empirical studies published in business journals and book chapters. As in the case of the General Theory of Marketing Ethics, most studies investigated the role that individual, personal, and work/professional environments play in ethical/ unethical behavior (e.g., Akaah 1989; Giacalone and Jurkiewicz 2003; McCabe et al. 2006; Soutar et al. 1994). The role of "governmental/legal environment" (described as legislation, administrative agencies, and judicial system within the proposed model) largely remained untouched.

Another widely cited model for understanding ethical behaviors of business organizations was proposed by Stead et al. (1990). The model involves three broad categories of factors: individual, organizational, and external. Individual factors encompass both personality (such as ego, Machiavellianism, and locus of control) and socialization (such as sex roles, religion, age, work experience, and significant others). Organizational factors include issues related to managerial philosophy and behavior, reinforcement system, and characteristics of the job. External factors are composed of economic conditions, scarce resources, competition, stakeholders, and political and social institutions (p. 237). Similar to other models, over the years, researchers have primarily investigated individual and organizational aspects of this model (e.g., Barnett et al. 1994; Cleek and Leonard 1998; Lere and Gaumnitz 2003; Mitchell et al. 1996; Winter et al. 2004).

Scholars of international business ethics suggested that company-specific factors such as existence of a written code of ethics, opportunities to discuss ethical issues within the company, size and the ownership type of the company, and extent of international involvement affect the ethical practices of companies that operate in different countries (Batten et al. 1999). In addition, culture accounts for a large part of the differences among the ethical decisions made by companies in different countries (e.g., Jing and Graham 2008; Lam and Shi 2008; Pitta et al. 1999; Sims and Gegez 2004; Srnka 2004). International business textbooks are full of examples warning managers of possible cultural conflicts regarding business ethics. Norms such as integrity, loyalty, honesty, and self-discipline vary greatly among people (Prasad and Rao 1982). People raised in different cultures hold different value systems and ethical understandings. As a macro factor affecting business decisions, culture is usually considered as given and the managers are expected to align themselves and their decisions based on cultural differences.

The above review suggests that even though potential impacts of political and legal environments of business on EBOF have been recognized, little empirical work has been produced to clarify their role. With respect to the "business environment," the existing literature suggests that industry type (e.g., Dornoff and Tankersley 1975; Oz 2001) and the level of competition (e.g., Hegarty and Sims 1978; Roberston and Rymon 2001) may have an impact on business ethics-related perceptions of managers. Most empirical work has focused on illustrating the impacts of other (individual, organizational, and situational) factors and, as a result, especially the influences of legal and political issues on business ethics have largely remained unknown. It may be unrealistic to expect all aspects of these 
comprehensive models to be investigated in a single study. Therefore, we do not suggest the exclusion of legal and political issues as a weakness of the previous studies. However, as suggested by Hunt and Vitell (2006), in order to advance our understanding of the EBOF, we believe that "researchers [should] focus attention on legal systems and political systems" (p. 147).

\section{Methodology}

This section provides information regarding the data-set used in the study, overview of the BCM method, procedures followed to identify institutional (political and legal) factors included in the study, and determination of the causal links among the institutional factors affecting EBOF.

\section{Data Source}

The data for this study come from a larger data-set of the Global Competitiveness Network of the WEF. The network, which has 150 partners around the world, collects data from two main sources: (1) standard international indicators (such as GDP) and (2) Executive Opinion Survey (EOS). The data used in this study come from a part of the EOS conducted with 13,000 executives in 139 countries (with an average of 95 respondents from each country) between January and May 2010.

As noted previously, WEF classifies countries into three distinct stages of development: factor-, efficiency-, and innovation-driven countries. Even though they are not exactly the same, this classification can roughly be treated as similar to the more commonly known classification of economic development, namely underdeveloped, developing, and developed countries. In WEF classification, two criteria are used to allocate countries into the stages of development prosperity (Sala-i-Martin et al. 2010). The first is the level of GDP per capita at market exchange rates. This widely available measure is used as a proxy for wages, because internationally comparable data on wages are not available for all countries covered. The thresholds identified by WEF are shown in Table 1 . The second criterion measures the extent to which countries are factor driven. This is measured by the share of exports of mineral goods in total exports (goods and services), assuming that countries that export more than $70 \%$ of mineral products (measured using a 5-year average) are to a large extent factor driven. Besides, any country falling in between two of the three stages is considered to be "in transition." As noted earlier, the entire WEF data were collected in 139 countries. However, since our analysis does not include the countries "in transition," the actual data for this study come from a total of 92 countries (31 Stage 1, 29 Stage 2, and 32 Stage 3 countries).

\section{Bayesian Causal Maps (BCM)}

This study utilizes BCM methodology. The BCM aids decision-making processes while accounting for uncertainty associated with the variables in the map. It makes it possible to structure the cause-effect relations as perceived by individuals and to make inferences using these perceived conditional relations (Nadkarni and Shenoy 2001). The first component of the BCM is causal maps. The construction of the causal maps requires capturing the causal knowledge of experts about a domain. Causal knowledge is especially important in the context of decision making because decision problems are described and understood through causal connections (Nadkarni and Shenoy 2004). These maps represent domain knowledge more descriptively than other models such as regression or structural equations. They express the judgment that certain events or actions will lead to particular outcomes and are formed by nodes representing causal concepts and links representing causal connections among causal concepts.

The second component of the BCM is Bayesian nets. The Bayesian nets, based on probability theory, are used where expert knowledge is uncertain and ambiguous. A fundamental assumption of the Bayesian net is that when we multiply the conditionals for each variable, we obtain the joint probability distribution for all variables in the network (Kemmerer and Shenoy 2007). As in causal maps, nodes represent the variables of the map, but this time, the links represent the conditional dependencies between the variables. If there is a directed link from a variable $X_{1}$ to a variable $X_{2}$, then $X_{1}$ is called as the parent of $X_{2}$ and $X_{2}$ as the child of $X_{1}$. Each variable in a Bayesian network $X_{1}, \ldots$, $X_{N}$ has a probability distribution given its parents and the product of these conditional probability distributions constitute the joint probability distribution of the network. The related formula can be written as in Eq. 1.

$P\left(X_{1}, \ldots, X_{N}\right)=\prod_{i=1}^{N} P\left(X_{i} \mid \operatorname{Pa}\left(X_{i}\right)\right)$

where $\operatorname{Pa}\left(X_{i}\right)$ denotes the set of parents of $X_{i}$. Based on this formula, it can be seen easily that the inference process is not based on one output variable in a Bayesian net.

The ability to reflect the complex dependency structure between the variables without compromising on any of the variables is the main advantage of Bayesian networks. They are especially useful in modeling uncertainty in a domain and have been applied particularly to problems that require diagnosis of problems from a variety of input data. They not only provide clear graphical structure with natural 
Table 1 Income thresholds for establishing stages of development

\begin{tabular}{ll}
\hline Stage of development & GDP per capita \\
\hline Stage 1: Factor driven ( $\sim$ underdeveloped) & $<2,000$ \\
Transition from Stage 1 to Stage 2 & $2,000-3,000$ \\
Stage 2: Efficiency driven ( $\sim$ developing) & $3,000-9,000$ \\
Transition from Stage 2 to Stage 3 & $9,000-17,000$ \\
Stage 3: Innovation driven ( $\sim$ developed) & $>17,000$
\end{tabular}

causal interpretation that most people find intuitive to understand; but also provide good estimates even when some predictors are missing (Nicholson et al. 2008).

Two different approaches have been used to construct Bayesian networks: one is data-based approach and the other one, that is also used in this study, is knowledgebased approach (Nadkarni and Shenoy 2004). The databased approaches use conditional independence theory to conduct models from data. The knowledge-based approach uses causal knowledge of domain experts in constructing networks. Nadkarni and Shenoy (2004) defines such maps as the most effective nets since they combine the qualitative structure based on expert knowledge with the quantitative probabilities identified and revised using hard data.

Thus, as a combination of causal maps and Bayesian nets, the BCM capture the causal knowledge of experts about a domain while allowing robust probabilistic inferences based on both causality and conditional independence. Although it resembles multiple regression in the way that there are dependent and independent variables, multiple regression treats only one item as a dependent variable, whereas the $\mathrm{BCM}$ has the ability to analyze more than one dependent variable at a time. Moreover, by the help of commercial software like Netica (the one that is used in this study), it is possible to conduct several what-if scenario analyses. The BCM methodology has been successfully used in various areas of economics and business, including the analysis of the complex and dynamic structure of inflation (Onsel-Sahin et al. 2006), environmental economics (Ülengin et al. 2010), venture capital decision making (Kemmerer and Shenoy 2007), and services (health care) management (Aktas et al. 2005).

In summary, the BCM methodology involves two main steps: (1) identification of a conceptual-causal map based on an expert panel and (2) "training" (analysis) of the conceptual-causal map with the actual data. In other words, using an expert panel, initially a conceptual-causal map is constructed. Then, the loops as well as redundant causal relations are eliminated from the map. Finally, the data for each concept are fed to the map in order to train the BCM. The following two sections provide details about the expert panel and the data analysis parts of this methodology.
Expert Panel: Identification of Factors and Causal Relationships

For the first stage of the BCM method, a survey was conducted to determine the variables to be used in the model which will serve as the basis for the analysis of EBOF. Seven academics who have expertise on business ethics were asked to choose the concepts that they thought had an influence on the EBOF among the 20 concepts of the first pillar of the GCI, namely "institutions." (Please see Appendix for the list of 20 concepts of the GCI) These experts were selected from different parts of the world (two from the United States, two from Europe, two from the Middle East, and one from Asia) and the survey procedure was performed through electronic (email) communication. The common characteristic of the expert panel members is that they either teach undergraduate and/or graduate levels business/marketing ethics courses and/or publish regularly in major business ethics journals such as the Journal of Business Ethics. The list of the resulting concepts that has been chosen by all of the experts is given in Table 2 .

After the determination of the concepts influencing EBOF, the experts compared these concepts in a pairwise matrix where the rows represented causes and the columns represented effects. The experts were asked to specify whether the relation between each pair of concepts was "positive," "negative," or "zero" (no relation). They were instructed to enter a "0" for no relation, "+" for a positive relation, and "-" for a negative relation in each cell to specify the relation between two concepts in the matrix. A total consensus was sought in order to gather the different points of view.

The relations were then analyzed in order to reveal reciprocal/circular causal relationships (i.e., the loops). The existence of loops is an indicator of the dynamic structure of any map (Eden and Ackermann 1998). However, the circular relationships or causal loops destroy the hierarchical form of the graph and violate the acyclic structure that is required by a BCM. For causal maps, no calculation has been developed that can cope with feedback cycles (Jensen 2002). Therefore, the map should not contain cycles. As a result, in the third stage, the identified loops were analyzed by subset of our expert team.

More specifically, if two concepts had reciprocal influences, then the one with the more dominant causal influence was determined. For example, it was stated that there was a causal link both from "irregular payments and bribes" (IPAB) to "strength of auditing and reporting standards" (SARS) and from "SARS" to "IPAB." After analyzing the situation, it was decided by the expert panel that the more dominant causal influence was the one from "SARS" to "IPAB." As a result, the link from "IPAB" to "SARS" was eliminated. In addition, one factor (strength 
Table 2 List of the variables directly/indirectly effecting EBOF

Intellectual property protection

Irregular payments and bribes

Judicial independence

Favoritism in decisions of government officials

Transparency of government policymaking

Strength of auditing and reporting standards

Efficacy of corporate boards

Strength of investor protection

of investor protection, SIP) that had been indentified in the first stage as a potential cause of EBOF was eliminated from further consideration as this factor was not considered as a cause for any other factors by our experts in the second round. The final pairwise matrix reached after above mentioned revisions is given in Table 3.

\section{Data Analysis Using BCM}

The BCM, as proposed by Nadkarni and Shenoy (2001), is a special type of causal map with an associated set of probability tables. In other words, the BCM is a combination of causal maps used for deterministic modeling and Bayesian networks used for uncertainty based modeling (Nadkarni and Shenoy 2001, 2004).

The map consists of the nodes, representing the concepts, and the arcs, representing relations between the concepts. The nodes of a BCM represent uncertain concepts and the arcs are the causal links between them (Fenton and Neil 2000). The BCM is a type of graphical model, which uses probability theory to manage uncertainty and complexity by explicitly representing the conditional dependencies between the nodes (concepts) (Jensen 2002). The visual representation of a BCM can be very useful in clarifying previously opaque assumptions or reasoning hidden in an expert's mind. From a mathematical point of view, the basic property of a BCM is the chain rule: a $\mathrm{BCM}$ is a compact representation of the joint probability table over its universe. In a simple Bayes net where $A$ affects $B$ and $B$ affects $C$; it is assumed that

$P(\mathrm{~A}, \mathrm{~B}, \mathrm{C})=P(\mathrm{~A}) \otimes P(\mathrm{~B} \mid \mathrm{A}) \otimes P(\mathrm{C} \mid \mathrm{B})$,

where $\otimes$ denotes pointwise multiplication of tables. In fact, the rule of total probability tells us that

$P(\mathrm{~A}, \mathrm{~B}, \mathrm{C})=P(\mathrm{~A}) \otimes P(\mathrm{~B} \mid \mathrm{A}) \otimes P(\mathrm{C} \mid \mathrm{A}, \mathrm{B})$

The difference between these two expressions depends on the assumption that $P(\mathrm{C} \mid \mathrm{A}, \mathrm{B})=P(\mathrm{C} \mid \mathrm{B})$, hence $\mathrm{C}$ is conditionally independent of A given $\mathrm{B}$. In other words, in Bayes nets, it is assumed that it is conditionally independent of its predecessors in the sequence given its parents meaning that missing arcs (from a node to its successors in the sequence) signify conditional independence assumptions. The fundamental assumption of a Bayesian network is that when the conditionals for each variable are multiplied, the joint probability distribution for all variables in the network is obtained (Mishra et al. 2001). In practice, such an approach is computationally intractable when there is an extensive number of variables since the joint distribution will have an exponential number of states and values.

Figure 1 shows a very simple BCM that consists of four variables, namely, judicial independence (JI), favoritism in decisions of government officials (FDGO), IPAB, and intellectual property protection (IPP). The dependence relations are expressed in terms of conditional probability distributions for each variable. Each variable has a set of possible values, called states. For illustrative purposes, these four variables have only three states, namely, low, medium, and high (please note that in the actual analysis each variable was expressed in five states; see Table 4). If there is an arrow from one variable to another, this means that there is a conditional dependence between these two variables, whereas the lack of an arrow signifies that the two variables are independent from each other. Thus, in our example JI and FDGO are independent of IPAB while IPP is dependent to FDGO and IPAB. Figure 1 also shows the conditional probability tables of $P(\mathrm{JI}), \quad P(\mathrm{FDGO} \backslash \mathrm{JI})$, $P(\mathrm{IPAB})$, and $P$ (IPP\FDGO, IPB). From these conditional probability tables, one can easily analyze the relations. For example, let us assume that the state of JI is known to be "low," then the probability of FDGO's being low is $88.97 \%$, being medium is $10.08 \%$, and being high is $0.94 \%$. Now suppose that the state of FDGO is known as "medium" and IPAB as "high", then IPP will be "low" with $0.52 \%$ probability, "medium" with $48.13 \%$ probability, and "high" with $51.34 \%$ probability.

Although the BCMs create an efficient language for building models of domains with inherent uncertainty, it may be time consuming to calculate conditional probabilities, even for a very simple BCM like the one given in Fig. 1, not to mention the model used in this study which has 8 variables, 20 conditional relations, and 32,680 conditional probabilities. Fortunately, there are several commercial software tools such as Hugin and Netica that can perform this operation. In the current research, Netica version 4.02 was used. It is a complete software package designed to work with BCMs, decision networks, and influence diagrams.

\section{Results}

The multiple iterations of the expert panel method revealed the final BCM illustrated in Fig. 2. The figure depicts the 
Table 3 Final pairwise matrix of the model

\begin{tabular}{|c|c|c|c|c|c|c|c|c|}
\hline & $\begin{array}{l}\text { Intellectual } \\
\text { property } \\
\text { protection }\end{array}$ & $\begin{array}{l}\text { Irregular } \\
\text { payments } \\
\text { and bribes }\end{array}$ & $\begin{array}{l}\text { Judicial } \\
\text { independence }\end{array}$ & $\begin{array}{l}\text { Favoritism in } \\
\text { decisions of } \\
\text { government } \\
\text { officials }\end{array}$ & $\begin{array}{l}\text { Transparency } \\
\text { of government } \\
\text { policymaking }\end{array}$ & $\begin{array}{l}\text { Strength of } \\
\text { auditing and } \\
\text { reporting } \\
\text { standards }\end{array}$ & $\begin{array}{l}\text { Efficacy } \\
\text { of } \\
\text { corporate } \\
\text { boards }\end{array}$ & $\begin{array}{l}\text { Ethical } \\
\text { behavior } \\
\text { of firms }\end{array}$ \\
\hline $\begin{array}{l}\text { Intellectual } \\
\text { property } \\
\text { protection }\end{array}$ & 0 & 0 & 0 & 0 & 0 & 0 & 0 & 1 \\
\hline $\begin{array}{l}\text { Irregular } \\
\text { payments and } \\
\text { bribes }\end{array}$ & 1 & 0 & 0 & 0 & 0 & 0 & 0 & 1 \\
\hline $\begin{array}{l}\text { Judicial } \\
\text { independence }\end{array}$ & 1 & 1 & 0 & 1 & 1 & 0 & 0 & 0 \\
\hline $\begin{array}{l}\text { Favoritism in } \\
\text { decisions of } \\
\text { government } \\
\text { officials }\end{array}$ & 1 & 1 & 0 & 0 & 0 & & 1 & 1 \\
\hline $\begin{array}{l}\text { Transparency of } \\
\text { government } \\
\text { policymaking }\end{array}$ & 0 & 1 & 0 & 1 & 0 & 1 & 0 & 0 \\
\hline $\begin{array}{l}\text { Strength of } \\
\text { auditing and } \\
\text { reporting } \\
\text { standards }\end{array}$ & 0 & 1 & 0 & 1 & 0 & 0 & 1 & 1 \\
\hline $\begin{array}{l}\text { Efficacy of } \\
\text { corporate } \\
\text { boards }\end{array}$ & 0 & 1 & 0 & 0 & 0 & 0 & 0 & 1 \\
\hline $\begin{array}{l}\text { Ethical behavior } \\
\text { of firms }\end{array}$ & 0 & 0 & 0 & 0 & 0 & 0 & 0 & 0 \\
\hline
\end{tabular}

direct and indirect relationships between $\mathrm{EBOF}$ and the remaining seven factors. The resulting BCM was then analyzed three times for each of the three different country (development) groups (Figs. 3, 4, 5) Before the analysis, each variable which was measured on a seven-point scale was divided into five probability categories (previously mentioned as states), ranging from "very low" to "very high". The cut-off ranges for each category are shown in Table 4.

The interpretation of the models derived from the BCM analysis can be done in two main ways: bottom-up and topdown approaches. Each type of interpretation provides researchers and decision makers a different perspective on how to improve the system which is composed of both dependent and independent variables. The bottom-up approach is useful in illustrating how the dependent variable is affected by the changes in each of the independent variables. In other words, through the use of the bottom-up approach, the researchers can identify how the possibilities of each state change in each of the factors influence the system as a whole. For example, when a state change from medium to very high in the JI occurs, then, the states of IPP, efficacy of corporate boards (ECB), and transparency of government policymaking (TGP) change from medium to high level, whereas EBOF changes from medium to very high.

The top-down approach, on the other hand, informs researchers and decision makers about what improvements need to be made in each of the variables so that the desired level of dependent variable can be achieved. For example, one can easily see that in order to change the level of EBOF from medium to high, there have to be changes in the states of IPP, IPAB, ECB, TGP, and JI from medium to high level as well as a change in FDGO from low to medium. Both bottom-up and top-down approaches provide information about the system in general.

More specific analyses can be done using the "sensitivity to findings" option of Netica. Sensitivity analysis identifies the variables having the most important impact on a dependent variable. A detailed investigation of these factors extracted from the sensitivity analysis is crucial because positive or negative changes in these factors have substantial impacts on the dependent variable. In the following sections, we first report the results of the BCM models and then provide results of the sensitivity analyses for each country group. 


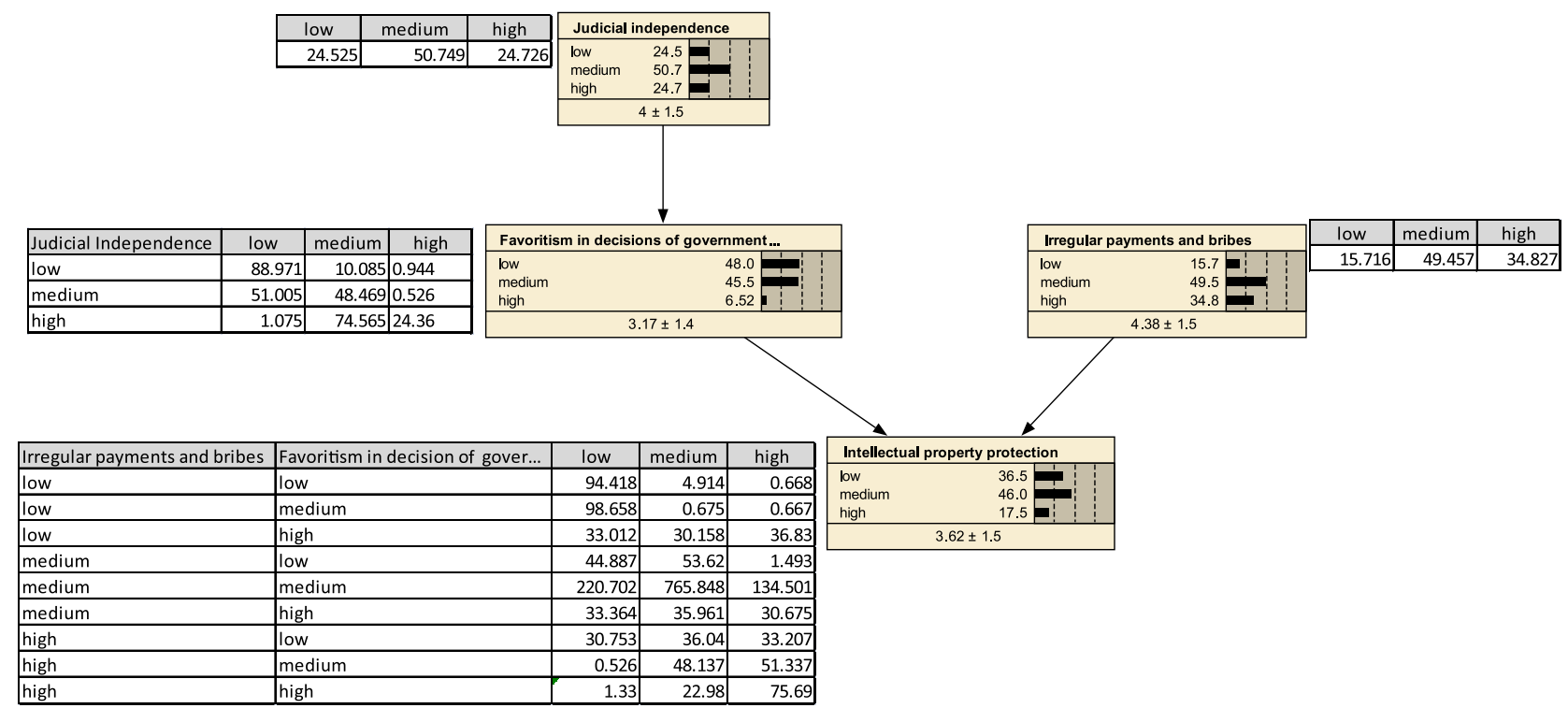

Fig. 1 An Illustration of BCM with conditional probability tables

Table 4 Probability categories (states)

\begin{tabular}{ll}
\hline Range & Category \\
\hline $1.00-2.20$ & Very low \\
$2.30-3.40$ & Low \\
$3.50-4.60$ & Medium \\
$4.70-5.80$ & High \\
$5.90-7.00$ & Very high \\
\hline
\end{tabular}

Results for Stage 3 Countries (Innovation-Driven, Advanced Economies)

Figure 3 suggests that given the current BCM model which consists of various political, legal, and business institutions,
EBOF operating in innovation-driven (advanced) economies is generally perceived as high. In other words, based on the existing variables and the causal relationships, there is a $75.8 \%$ (high: $33.1 \%$ + very high: $42.7 \%$ ) probability that managers who work in innovation-driven (advanced) economies perceive the behavior of their fellow managers who work in the same type economies as "highly" ethical.

In addition, the model suggests that each factor affecting EBOF in these advanced economies is perceived quite positively. The overall review of the model reveals that the only partially problematic variable appears to be FDGO. The probability that managers perceive FDGO as medium or lower in these innovation-driven economies is $66.5 \%$ (medium: $39 \%+$ low: $26.6 \%$ + very low: $0.93 \%$ ).

Fig. 2 The BCM for the EBOF

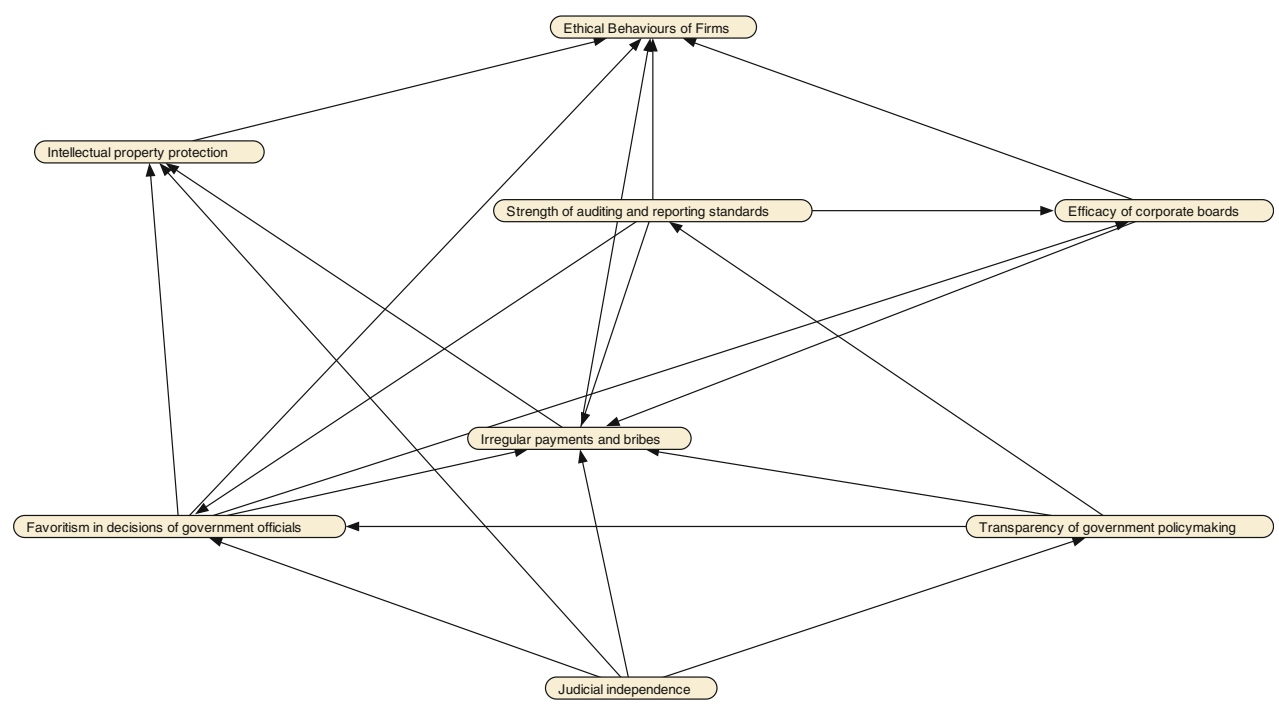




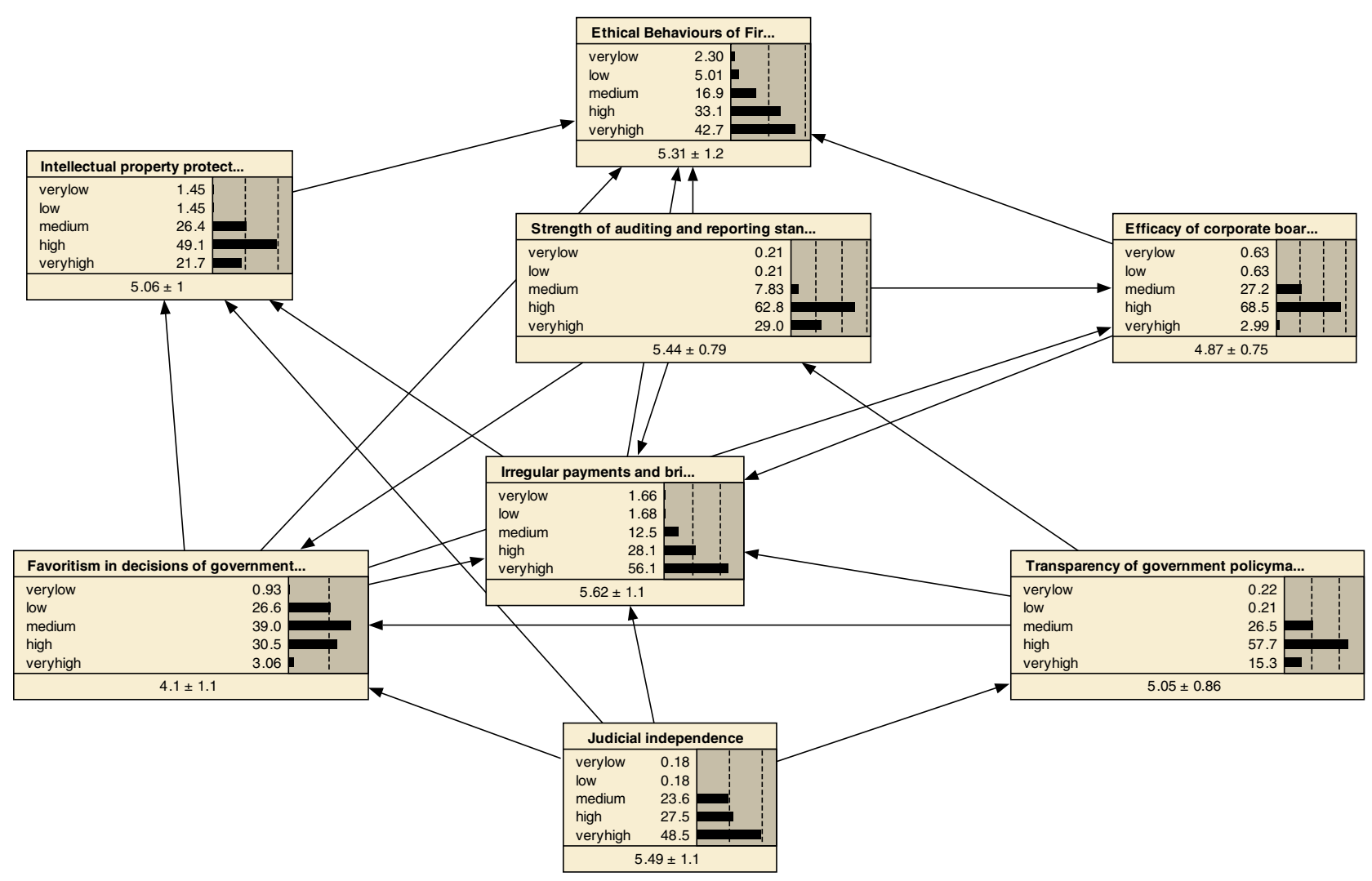

Fig. 3 The BCM of EBOF for Stage 3 countries

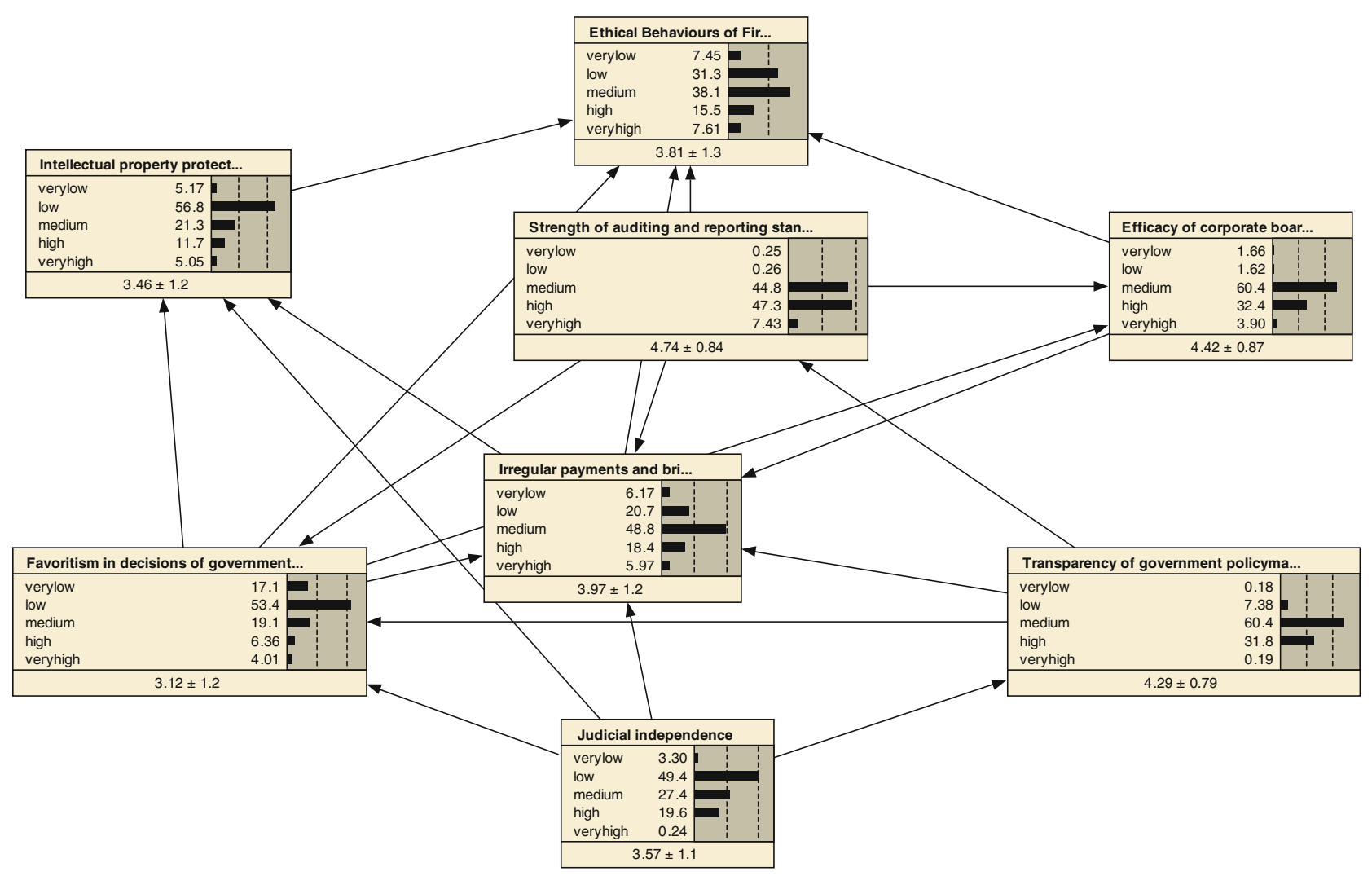

Fig. 4 The BCM of EBOF for Stage 2 countries 


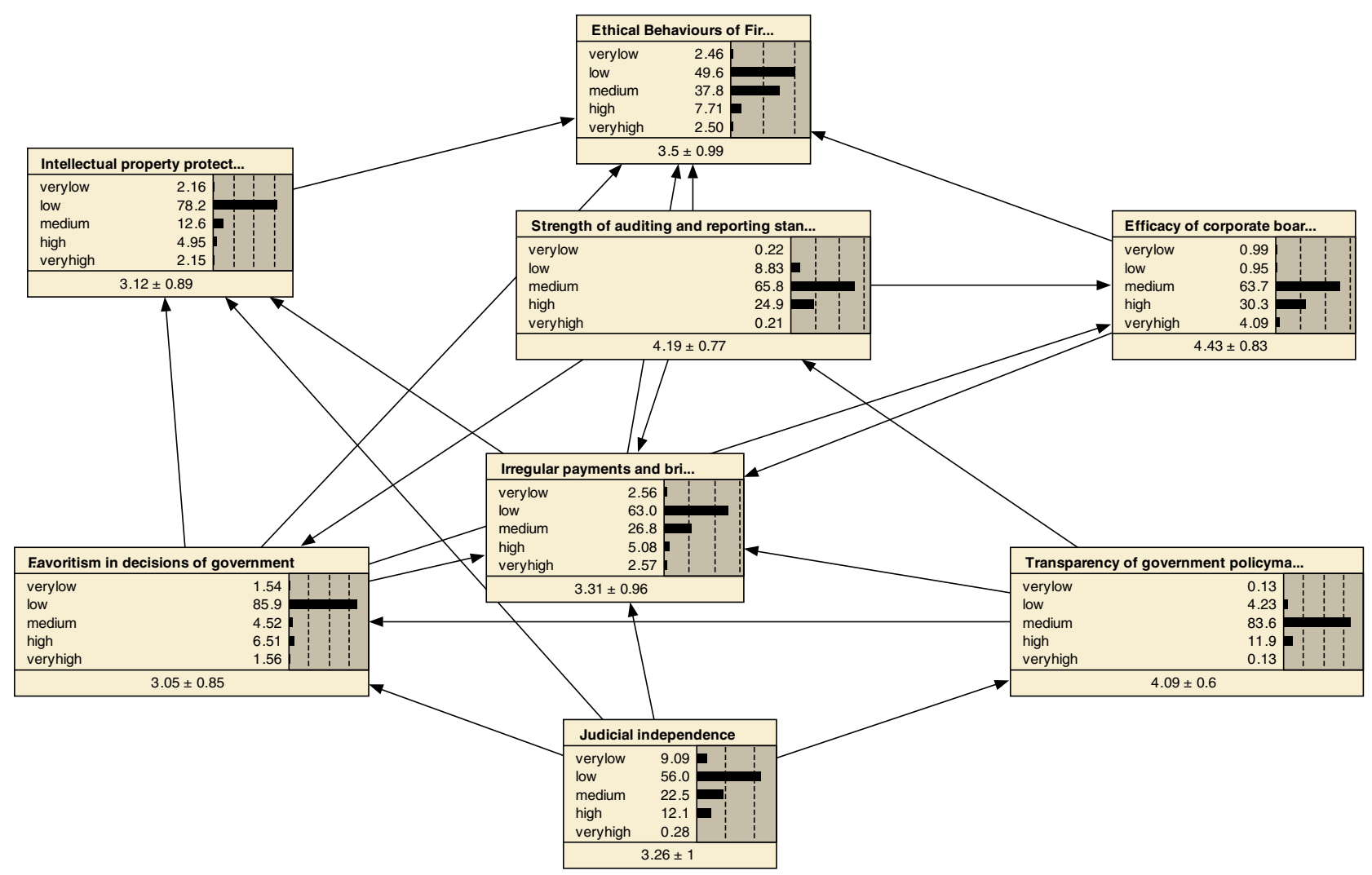

Fig. 5 The BCM of EBOF for Stage 1 countries

A more detailed look at the relationships given in Fig. 3 require a sensitivity analysis. In this way, we can easily analyze how much our belief in a particular node (factor) is influenced by the findings at other nodes (factors). The sensitivity analysis of the BCM for innovation-driven economies has shown that the most significant factor on the EBOF is IPAB, followed by FDGO, and IPP. Furthermore, a detailed sensitivity analysis identifies JI as the most influential factor on IPAB in Stage 3 countries. We will provide a more detailed discussion about these most influential factors later in this section.

Results for Stage 2 Countries (Efficiency-Driven, Developing Economies)

An overview of the BCM for the Stage 2 countries (i.e., the efficiency driven, developing economies) suggests that managers who work in these countries perceive ethical behavior of fellow managers who also work in similar countries generally as medium or low (but definitely not high). A closer look at each factor indicates that issues related to IPP, FDGO, and JI are particularly perceived to be low in these countries.

The sensitivity analysis of the BCM for Stage 2 countries has yielded almost the same results as the Stage 3 countries in that the most significant factor on the EBOF is IPAB, followed by FDGO, and IPP. Furthermore, as in the case of the Stage 3 countries, a detailed sensitivity analysis has identified JI as the most influential factor on IPAB for the Stage 2 countries.

Results for Stage 1 Countries (Factor-Driven, Underdeveloped Economies)

As can be seen in Fig. 5, given the existing model and the causal relationships among the variables, managers in factor-driven economies perceive the EBOF operating in similar countries generally as low. Issues related to FDGO, IPP, IPAB, and JI appear particularly problematic ("low" probabilities are 85.6, 78.2, 63, and $56 \%$, respectively). However, without a sensitivity analysis, any conclusion regarding the most influential factors on EBOF operating in factor-driven economies would be misleading.

As compared to the Stage 3 and Stage 2 countries, for Stage 1 countries, the order resulting from the sensitivity analysis reveals a different pattern, making IPP the most influential factor affecting ethical behavior, followed by FDGO and JI. However, as in the case of the Stage 2 and the Stage 3 countries, a further sensitivity analysis on the 
IPP variable reveals once again JI as the key factor affecting perceptions of IPP in Stage 1 countries.

Detailed Analysis for Stage 3 and Stage 2 Countries

When we employ the top-down approach to the results of the sensitivity analysis for Stage 3 and Stage 2 countries (Figs. 6, 7), we see that any improvement on EBOF is closely linked to the improvements these countries can make in IPAB. As a result, if countries would like to improve EBOF operating in their countries, they should improve their performance on IPAB (i.e., they should take measures to lower perceptions of corruption and bribery among the business people in the country).

Similarly, when we focus on the IPAB and again use the top-down approach, the sensitivity analysis reveals JI as the most influential factor on IPAB. As can be seen in Figs. 8 and 9, in order to improve IPAB both in Stage 3 and in Stage 2 countries, a significant improvement in the JI would be required.

JI, located at the bottom of all the models, is considered as the critical factor (the "policy variable") as it affects all the other factors yet is not affected by any other factor in the system. Therefore, since changes in policy variables have considerable impacts on the entire system, their analyses may reveal important results. The following two figures delineate potential changes among the most crucial three factors in the business ethics systems in Stage 3 and Stage 2 countries. As can be seen in Fig. 10, when JI is elevated from medium to high, and to very high levels, the factor it ultimately affects the most (EBOF) improves from medium to high, and to very high immediately.

Similarly, if JI can be improved to medium and to high from low, EBOF operating in Stage 2 countries improve from low to medium, and to high (see Fig. 11).

\section{Detailed Analysis for Stage 1 Countries}

As indicated earlier, factor-driven economies (Stage 1 countries) show a different pattern than both efficiencydriven economies (Stage 2 countries) and innovation-driven economies (Stage 3 countries). In other words, when we employ the top-down approach to the results of the sensitivity analysis for Stage 1 countries, we see that any
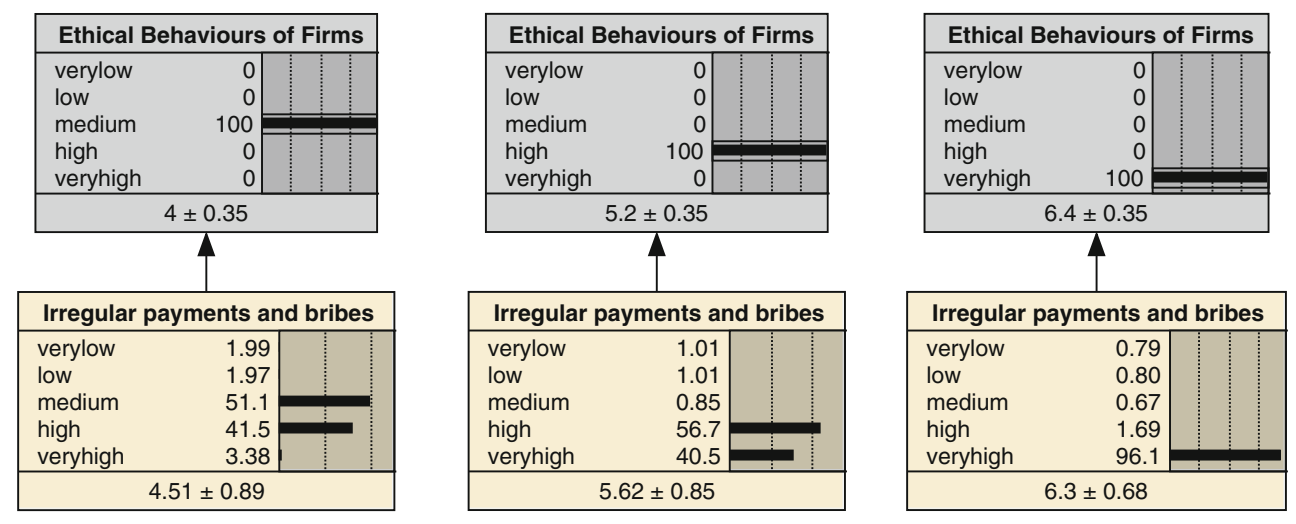

Fig. 6 Relationship between EBOF and IPAB in Stage 3 countries
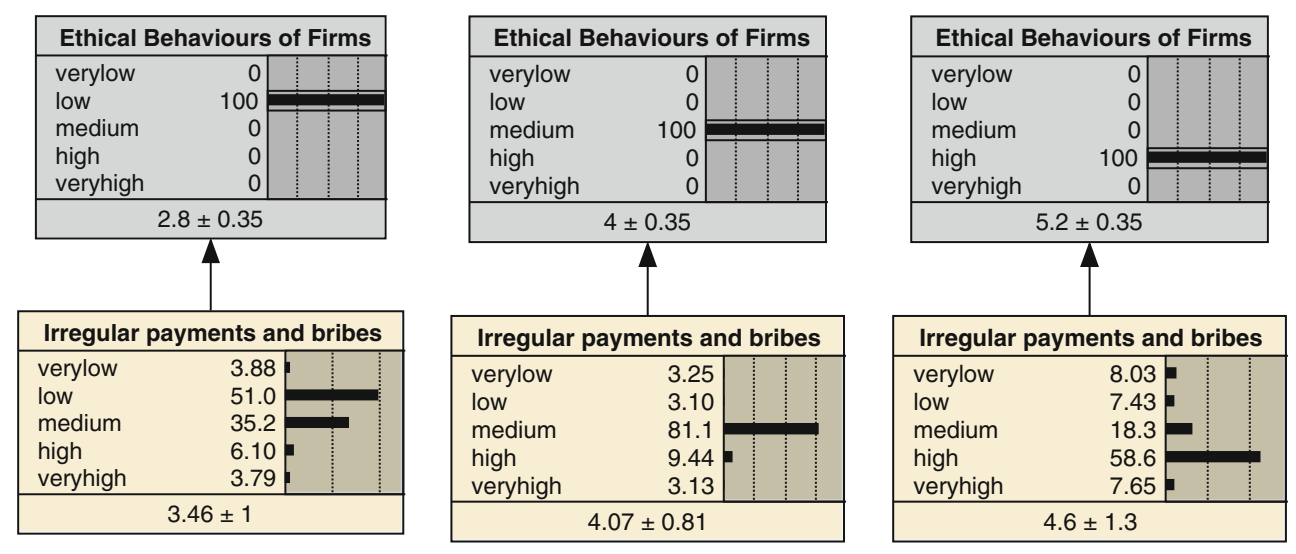

Fig. 7 Relationship between EBOF and IPAB in Stage 2 countries 

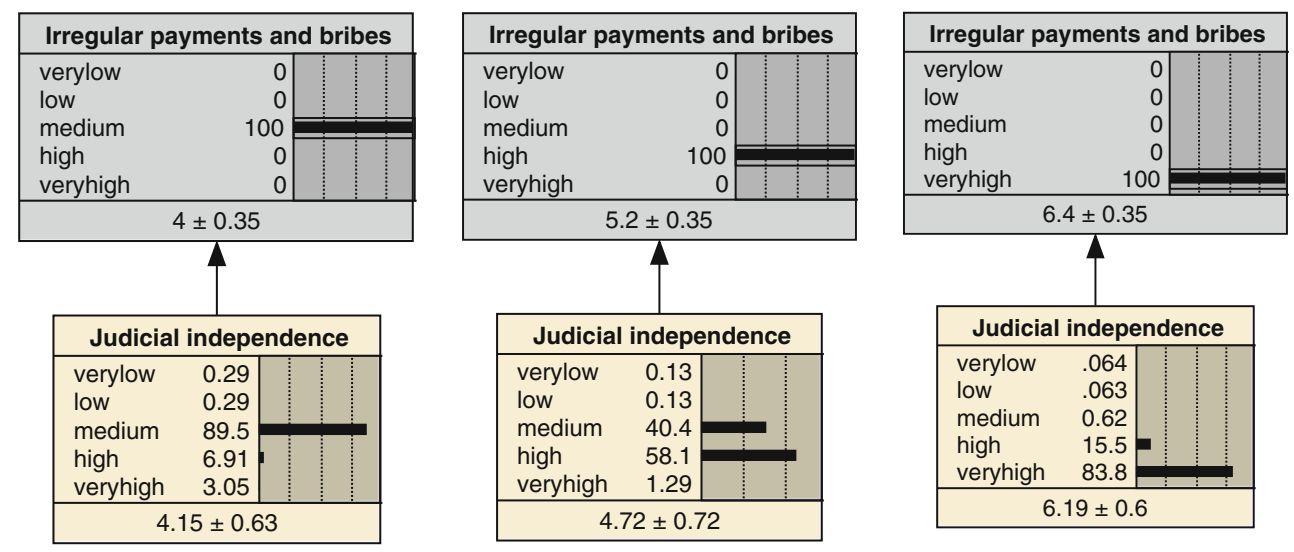

Fig. 8 Relationship between JI and IPAB in Stage 3 countries
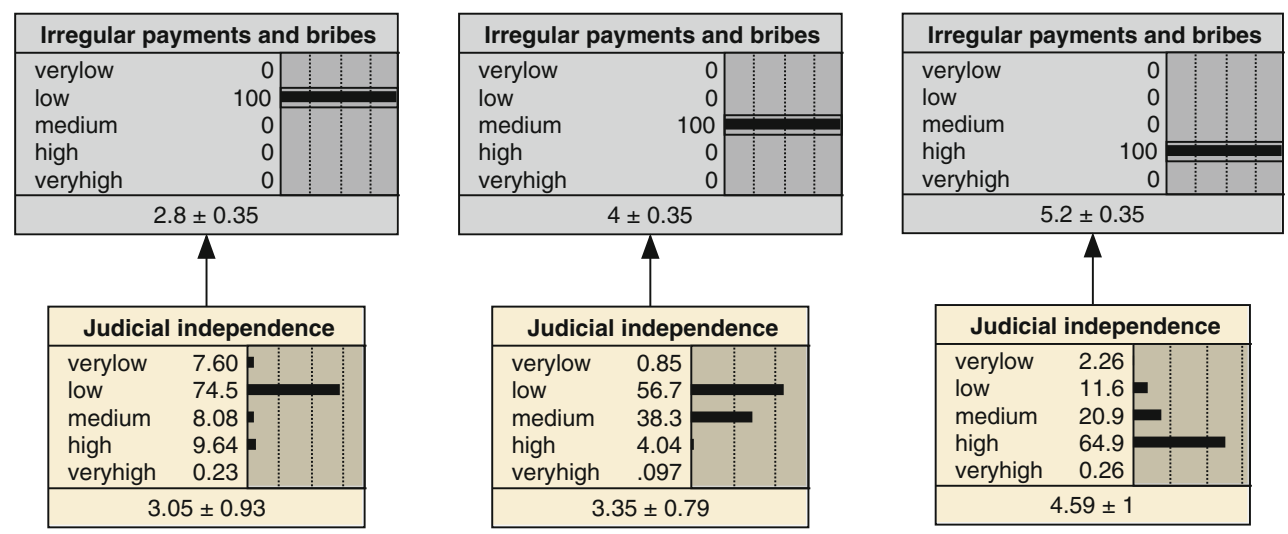

Fig. 9 Relationship between JI and IPAB in Stage 2 countries
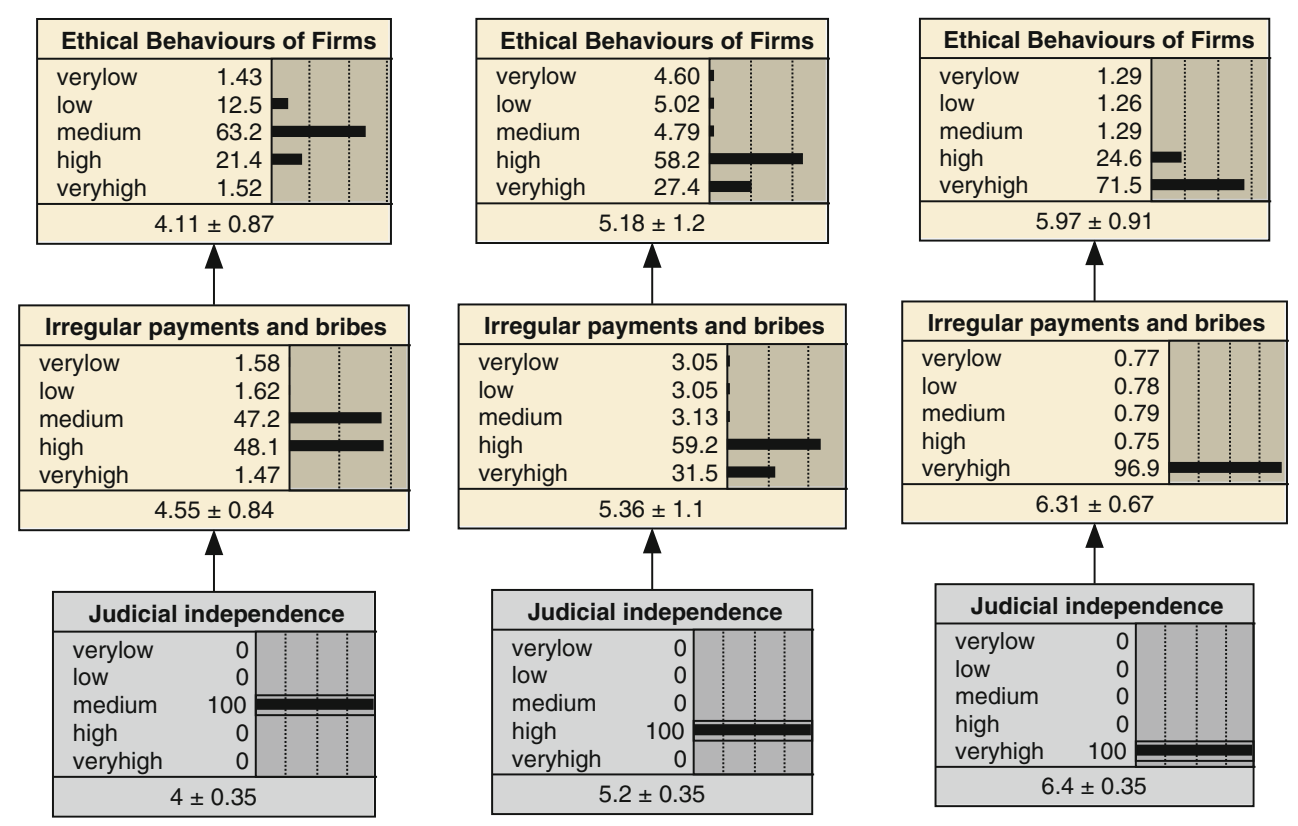

Fig. 10 Relationship between JI and EBOF in Stage 3 countries 

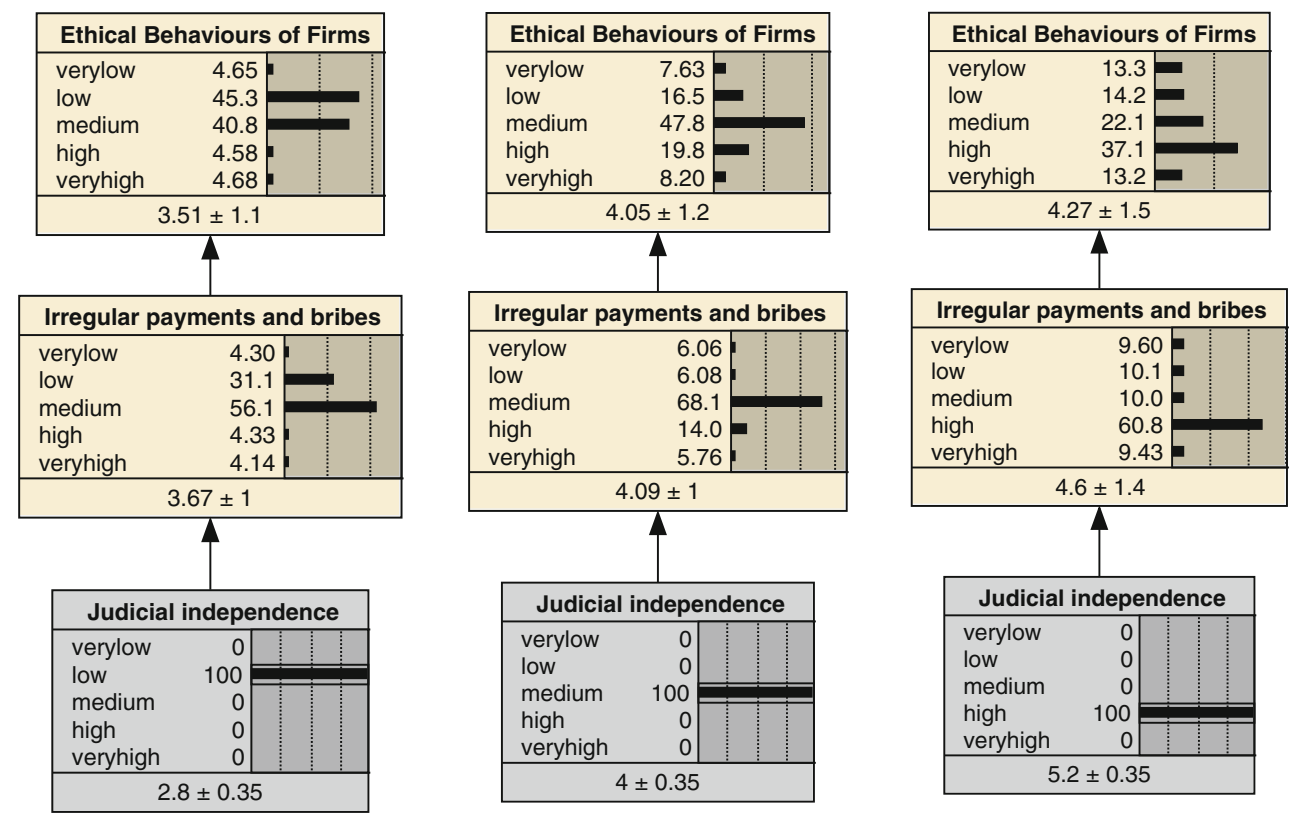

Fig. 11 Relationship between JI and EBOF in Stage 2 countries
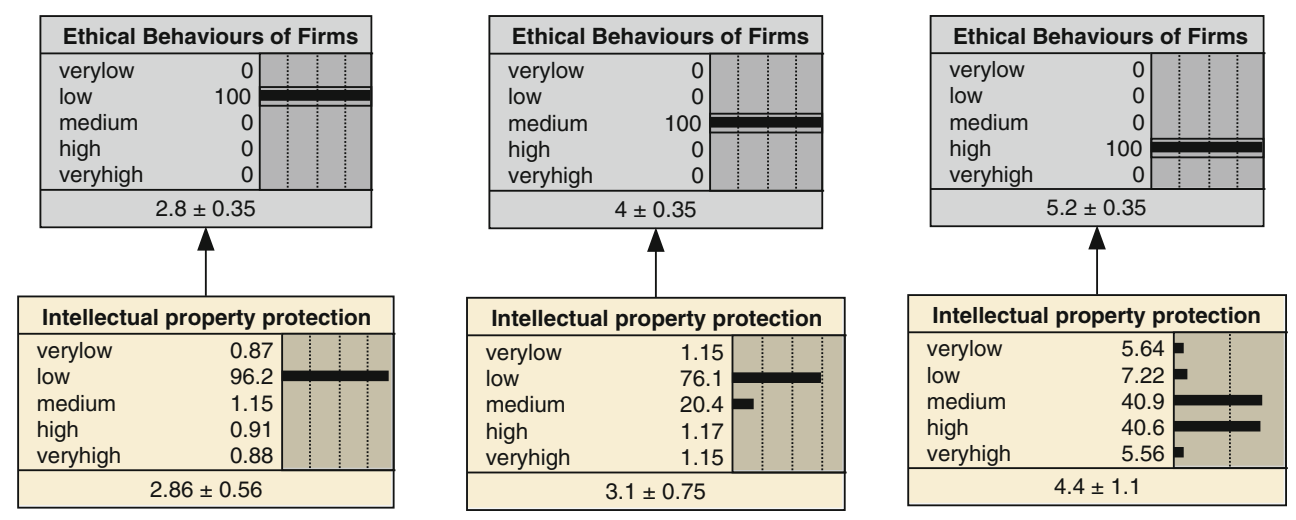

Fig. 12 Relationship between EBOF and IPP in Stage 1 countries

improvement on EBOF will be closely linked to the improvements these countries can make in IPP. As a result, if Stage 1 countries would like to improve EBOF operating in their countries, they would have to improve their performance on IPP (see Fig. 12).

Similarly, when we focus on IPP and again use the topdown approach, the sensitivity analysis reveals JI as the most influential factor on IPP. As can be seen in Fig. 13, in order to improve IPP in Stage 1 countries, a significant improvement in the JI would be required.

As in the case of Stage 2 and Stage 3 countries, JI is also the policy variable in Stage 1 countries, and therefore, a further analysis of JI is likely to reveal fruitful results. Figure 14 delineates potential changes among the most crucial three factors in the business ethics system in Stage 1 countries. As can be seen in Fig. 14, when JI is elevated from low to medium and to high, the factor it ultimately affects the most (EBOF) improves immediately.

\section{Conclusion}

The objective of this study was to advance our current understanding of the factors affecting EBOF. Toward this end, we particularly focused our attention on relatively less-studied aspects of business ethics: the political and legal environments of business. Using a panel of business ethics experts, we identified a model that depicts how certain legal and political factors affect EBOF. The model, then, was applied to three distinct country types: innovation-, efficiency-, and factor-driven countries. We observed 

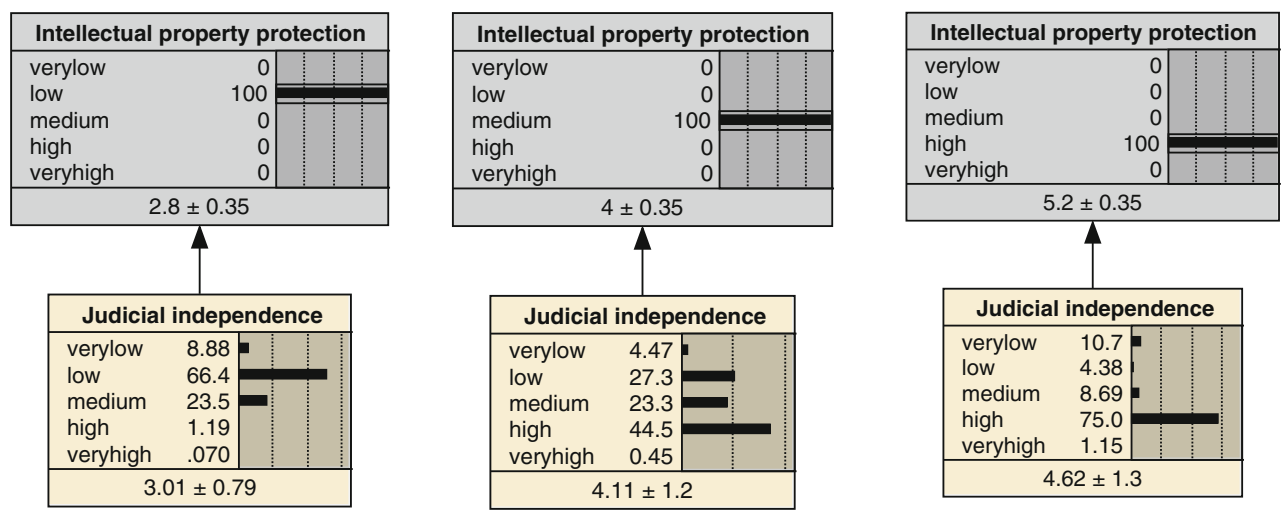

Fig. 13 Relationship between JI and IPP in Stage 1 countries
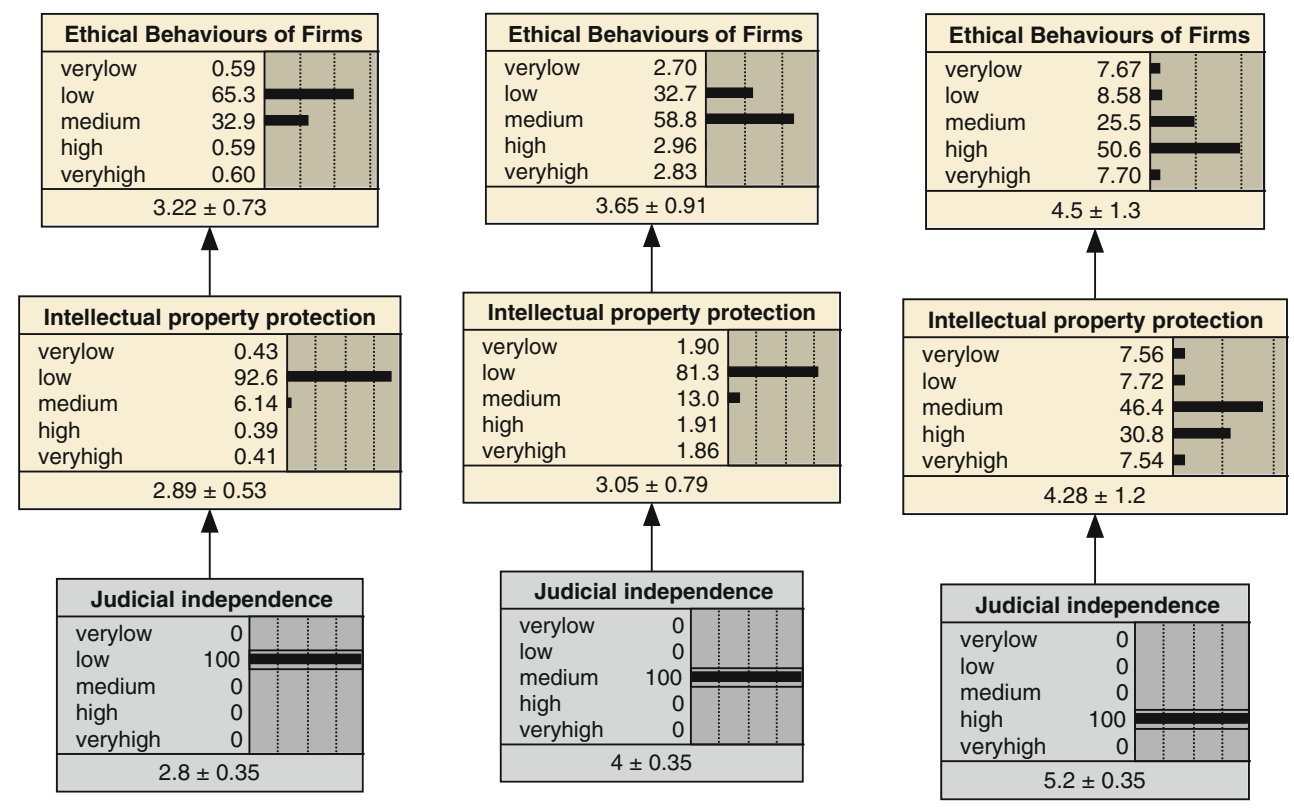

Fig. 14 Relationship between JI and EBOF in Stage 1 countries

that EBOF diminishes as we move from more advanced (innovation-driven) to less-advanced (efficiency-driven and factor-driven) countries. Even though the same model is executed, we notice important differences in the way political and legal environments (factors) influence EBOF in each country group. Despite significant differences across the country groups, one striking similarity, however, is the importance of JI for a better (or worse) ethical conduct throughout the world. This section discusses our major findings, their managerial and public policy implications, and future research directions.

\section{Significance of JI}

The results of the sensitivity analysis reveal a similar pattern for both Stage 3 and Stage 2 countries. In both cases, the most influential factor affecting EBOF was IPAB, followed by FDGO. The only difference we observed was the percentage probabilities of each factor. When IPAB was put through a further sensitivity analysis, JI was identified as the most influential factor affecting IPAB. For Stage 1 (factor-driven) countries, the order resulting from sensitivity analysis was different, making IPP the most influential factor affecting ethical behavior, followed by FDGO. A further sensitivity analysis on the IPP variable reveals once again JI as the key factor affecting perceptions of IPP in Stage 1 countries. This result, along with the results of Stage 3 and Stage 2 countries, may suggest that at the bottom line, regardless of the development stage, the level of EBOF is closely tied to the perceptions of JI in a particular country. In other words, regardless of where the business is conducted in the world, perceived independence of courts and judges is critical for an improved ethical conduct of businesses. 
The Differentiating Role of Corruption and Bribery

Based on Economic Development

As noted previously, the results of the sensitivity analysis identified IPAB as the most significant factor on EBOF operating in Stage 3 and Stage 2 countries. However, when it comes to the Stage 1 countries, the sensitivity analysis revealed IPP as the most influential factor on EBOF. In fact, IPAB does not even appear among the most important factors affecting business ethics for the managers who work in these less-developed (factor-driven) economies (listed as the fourth out of seven factors). Based on the Transparency International Report (2010), one might expect corruption and bribery to have a greater impact on business activities (and correspondingly on business ethics) in less-developed countries. So, how can we explain our findings?

Management and business scholars, as well as anthropologists and business analysts have argued that issues related to corruption and bribery may be a function of cultural context within which moral decisions regarding business are made (e.g., Blundo and Olivier de Sardan 2006; Chabal and Daloz 1999; Velasquez 2010). For example, Velasquez (2010) argues that as corruption in general and bribery in particular are considered unethical in most developed and developing countries, they may not necessarily be viewed as acts of violation of business ethics in certain cultural contexts. Furthermore, he argues:

...it is morally wrong to offer and/or accept bribe-

s...in countries where the norms and expectations

that govern official roles are relatively clear and well

known, and where the public-private distinction is

recognized, accepted, and well-entrenched in the

bureaucratic institutions in the society. The devel-

oped nations and many of the developing ones fall

into this category" (p. 487).

In such countries, for business people to offer IPAB to officials may be considered unethical because such an act may result in the use of public power for private purpose. However, in societies where the public-private distinction is neither commonly recognized nor accepted, various forms of corruption including bribery, favoritism, or nepotism may not be considered morally unacceptable. When government is not understood as a public entity whose primary purpose is to serve the interests of the public (in other words, when the boundary between the public and private interests of the individuals blur), offering IPAB to either government officials or other fellow business people may not be viewed as an unethical business practice (or may be viewed as a morally neutral act).

The results of our study may offer empirical support for the notion that bribery may not be viewed as a critical issue of business ethics in certain countries. The countries depicted in the writings of Blundo and Olivier de Sardan (2006); Chabal and Daloz (1999) and Velasquez (2010) are all classified as Stage 1 countries in our study. Many of these countries are characterized not only by low income but also by undemocratic, autocratic, or monarch governments including some of the Arab sheikhdoms and sultanates, Nepal, and postcolonial regimes of sub-Saharan Africa. Even though according to Transparency International, corruption and bribery is a common practice in these countries, they may not be perceived as morally wrong conducts of business. As our results show, for managers of the companies operating in Stage 1 countries, IPAB is not a very important factor affecting their perceptions of the level of business ethics in these countries. Therefore, it may be concluded that bribery affects business decisions, but not the perceptions of business ethics in Stage 1 countries.

\section{The Role of IPP}

Our study reveals a crucial link between IPP and business ethics in Stage 1 countries. As can be seen in Fig. 15, when the current level of IPP (which is quite low, see Fig. 5) can
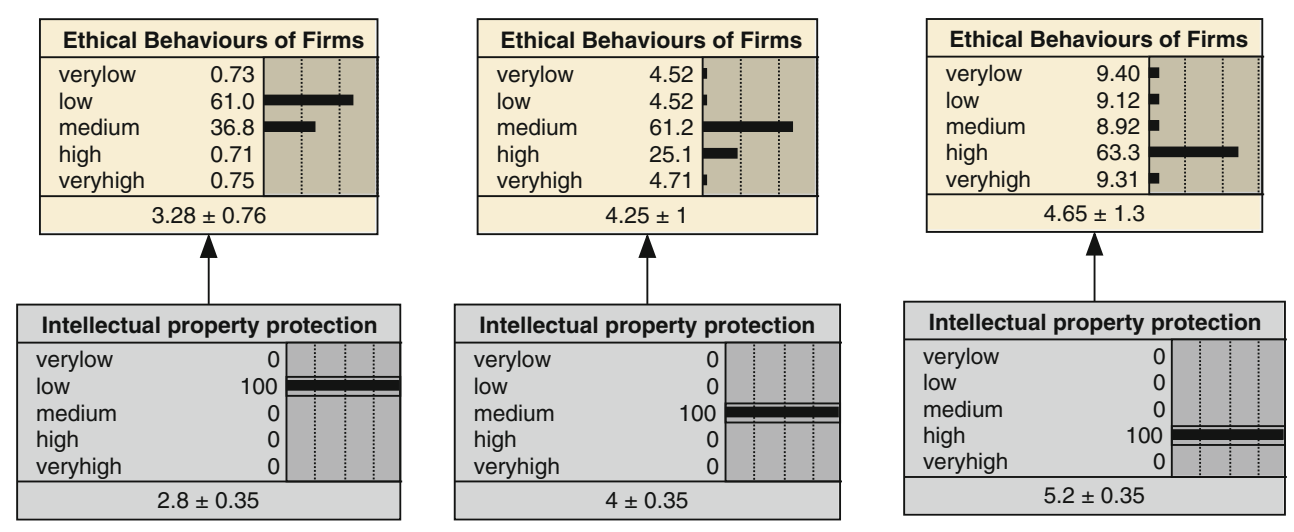

Fig. 15 Relationship between IPP and EBOF in Stage 1 countries 
be improved to medium or to high, EBOF improves to medium or to high immediately. Establishing an effective IPP system in the underdeveloped world appears as the most significant factor affecting managers' perceptions of business ethics in these countries. However, as recent reports point out, instituting effective IPP systems in the underdeveloped world is a daunting task (e.g., Britz and Lipinski 2001; Kameri-Mbote 2005; Sikoyo et al. 2006). Considering that most (about $60 \%$ ) Stage 1 countries in our study are from Africa (see Table 5), we would like to particularly discuss a few important issues and challenges related to IPP in Africa. As indicated by Sikoyo et al. (2006), even though most of the countries in Africa have taken measures to comply with international IPP standards,

Table 5 Country groupings identified by WEF

\begin{tabular}{|c|c|c|}
\hline $\begin{array}{l}\text { Stage } 3 \text { countries } \\
\text { (Innovation-driven) }\end{array}$ & $\begin{array}{l}\text { Stage } 2 \text { countries } \\
\text { (Efficiency-driven) }\end{array}$ & $\begin{array}{l}\text { Stage } 1 \text { countries } \\
\text { (Factor-driven) }\end{array}$ \\
\hline Australia & Albania & Chad \\
\hline Austria & Argentina & Côte d'Ivoire \\
\hline Belgium & $\begin{array}{l}\text { Bosnia and } \\
\text { Herzegovina }\end{array}$ & Ethiopia \\
\hline Canada & Brazil & Gambia \\
\hline Cyprus & Bulgaria & Ghana \\
\hline Czech Republic & Cape Verde & Honduras \\
\hline Denmark & China & India \\
\hline Finland & Colombia & Kenya \\
\hline France & Costa Rica & Kyrgyz Republic \\
\hline Germany & Dominican Republic & Lesotho \\
\hline Greece & Ecuador & Madagascar \\
\hline Hong Kong SAR & El Salvador & Malawi \\
\hline Iceland & Jordan & Mali \\
\hline Ireland & Lebanon & Mauritania \\
\hline Israel & Macedonia FYR & Moldova \\
\hline Italy & Malaysia & Mongolia \\
\hline Japan & Mauritius & Mozambique \\
\hline Korea Rep & Mexico & Nepal \\
\hline Luxembourg & Montenegro & Nicaragua \\
\hline Malta & Namibia & Nigeria \\
\hline Netherlands & Panama & Pakistan \\
\hline New Zealand & Peru & Philippines \\
\hline Norway & Romania & Rwanda \\
\hline Portugal & Russian Federation & Senegal \\
\hline Singapore & Serbia & Tajikistan \\
\hline Slovenia & South Africa & Tanzania \\
\hline Spain & Thailand & Timor-Leste \\
\hline Sweden & Tunisia & Uganda \\
\hline Switzerland & Turkey & Vietnam \\
\hline United Arab Emirates & & Zambia \\
\hline United Kingdom & & Zimbabwe \\
\hline United States & & \\
\hline
\end{tabular}

the effective implementation of these norms has not become possible due to various shortcomings including limited understanding of intellectual property rights (IPRs) and lack of people and institutions with sufficient experience and knowledge to handle IPRs, particularly with respect to investment, trade, and competition.

After reviewing current research, knowledge, practices, and challenges of IPR issues in various African countries, Kameri-Mbote (2005) and Sikoyo et al. (2006) have made a number of recommendations to improve IPP standards around the region. The main argument these scholars put forward is that considering historical, cultural, socioeconomic, and resource characteristics, a search for an alternative IPP regime may need to be considered for Africa. As specified by Sikoyo et al. (2006):

The search for the alternative IP should be driven by compatibility with the indigenous alternative rights/ systems. These need not be predetermined, but need to be well thought out and articulated outside the fixed IP categories. Flexibility should guide the process where the African countries are able to mould IPR regimes that work for them, and the region as a whole (p. 28).

Interestingly, even though both of these reports were written in two different time frames and covered different parts of (sub-Saharan) Africa, they both concluded exactly the same set of assessments of IPR needs and made similar recommendations to meet these needs. In summary, in order to improve IPP in the region, national infrastructure (including information technology facilities, good record keeping practices, accurate statistical data, and internet access), and human resources capacity (e.g., staffing of trained IP personnel and scientists with understanding of law and trade) should be enhanced. In addition, legal practices related to IPP need to be extended, and as law schools invest more on programs covering IP issues, training programs should be offered for those who graduated from law schools with no IP-law education. On a related issue, it was noted that since litigation on IPR is quite low in African countries, judges are not able to develop experience through practice. As a result, there seems to be a need for creating greater awareness in the judiciary to both understand and interpret IP-related laws.

Other Managerial and Public Policy Implications

The models depicted in this paper can potentially provide a useful diagnostic tool for (international) companies and public policy makers. However, given inherit limitations of the expert panel method used in this study both policy makers and other (managerial) practitioners should use our models cautiously. First, by using our models, companies 
who intend to enter into one of the three types of economies (Stage 1, 2 or 3 countries) may be equipped beforehand about the dynamics of business ethics in that particular type of economy. More specifically, managers of international companies may be able to know how certain legal and political issues of business affect the business ethics system in that type of economy. This information, in turn, may help companies to have more informed decisions about their entry strategies.

Second, by using our models, managers can assess the overall business ethics climate of the particular country that they plan to enter, and as a result, take necessary precautions before the entry. For example, let us assume that an Australian company (currently operating in a Stage 3 economy) is planning to enter into two former-socialist countries: Romania (a new EU member and a Stage 2 country) and Moldova (a former Soviet Union state and a Stage 1 country). Based on the classification scheme given in Table 3, our data indicate that Romania scores "low" on IPP (3.2), FDGO (2.4), and TGP (2.9); and "medium" on IPAB (4.4), JI (3.5), SARS (4.6), and ECB (4.4). Moldova, on the other hand, scores "low" on IPP (2.6), IPAB (3.3), JI (2.3), and FDGO (2.7); and "medium" on SARS (4.3), ECB (4.4), and TGP (4.3). When the models we propose in this study (i.e., models for Stage 2 and Stage 1 economies) are treated with the above scores, one can observe that there is a high probability that EBOF in both countries will be "low." More specifically, given certain legal and political factors and the interactions among them, there is a $61.9 \%$ chance that the EBOF in Romania will be low. Similarly, there is even a greater chance $(68.5 \%)$ that the EBOF operating in Moldova will be low (Fig. 16a, b). Even though these results may seem discouraging for the Australian firm, they may indeed help the company to be better prepared for these new markets. For example, the Australian company may decide to put more emphasis on the rules governing their business conduct. If the company did not have a written ethical code, perhaps it is time to adopt one so that their managers can be better guided in these new countries where the business ethics is perceived to be low. The literature suggests that companies having a written code of ethics are less likely to engage in unethical business practices in the international markets (e.g., McKinney and Moore 2008). In this example, a hypothetical Australian company was chosen to demonstrate possible managerial implications of our models. Similar scenarios can be developed and corresponding managerial implications can be drawn for any company in the world that plans to enter into any of the 92 countries included in this study. Similarly, based on the models depicted in this study, governments across the world may be able to develop scenarios and related public policies in order to improve the business ethics climate in their countries.

\section{Final Remarks and Future Research}

This research can be considered as one of the rare examples that empirically examines the relationships between the legal and political environments of business and EBOF. The models reported in this paper clearly delineate how EBOF is related to each of the seven environmental factors. Moreover, for each of the three development stages, the results of the sensitivity analyses pinpoint the most crucial factors affecting EBOF. Both through the overall models and through the sensitivity analyses, our study provides directions for policy makers to improve the ethical conduct of businesses in their respective countries. In addition, the results of this study provide further support for scholars who argue that business ethics is likely to vary among countries based on their socio-economic factors (e.g., Batten et al. 1999; Robertson 2009). The data for our study, which come from 92 countries in the world, provide a rather convincing argument for the thesis that business ethics is related to the countries' development stage.

Furthermore, the BCM methodology allows researchers to analyze a domain from a systems perspective. As a
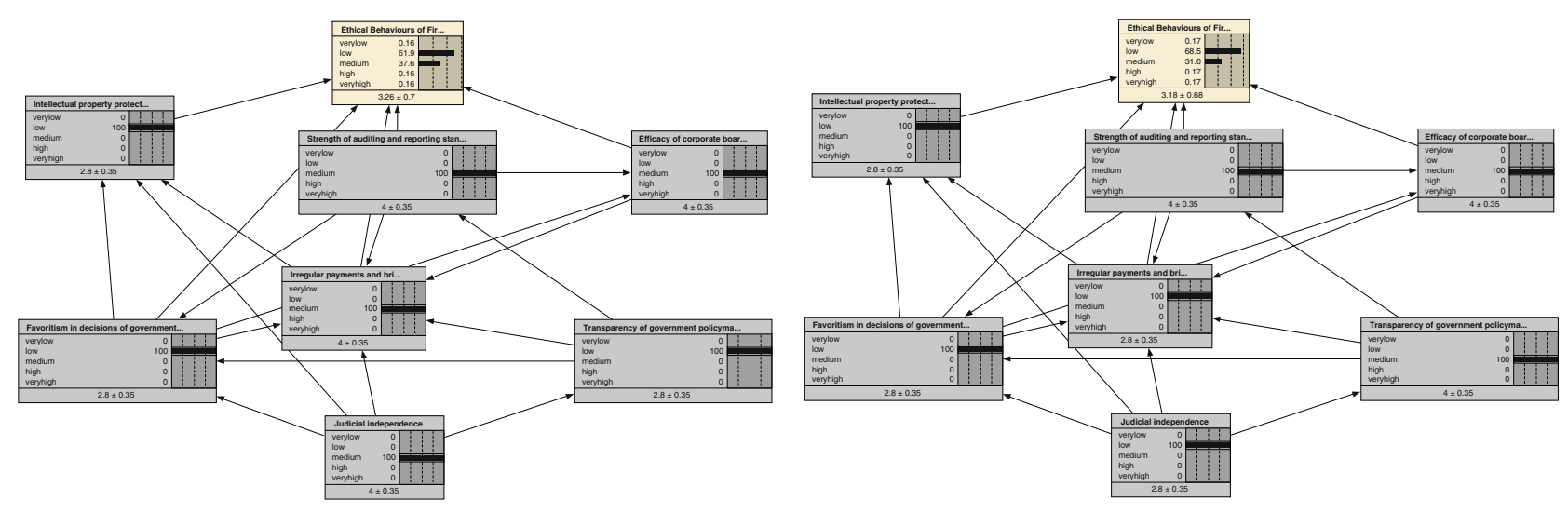

Fig. 16 a EBOF probabilities for Romania b EBOF probabilities for Moldova 
result, in addition to explaining how various legal and political environmental factors affect business ethics, we are able to delineate causal interrelationships among the legal and political factors depicted in the models. Finally, this study, to the best of our knowledge, is the first application of the BCM methodology for a business ethics topic. As noted earlier, the BCM is considered one of the most powerful techniques in capturing the causal knowledge of experts about a domain. These maps represent domain knowledge more descriptively than other models such as regression and structural equations. We believe that the adaptation of this methodology by other researchers is likely to be beneficial for the theory and practice of business ethics. This way, we may both advance our understanding of the factors affecting ethical decisions and improve ethical decision-making processes.

Since IPAB are the leading factors affecting managers' perception of business ethics in Stage 3 and Stage 2 countries, future research that investigates the dynamics of firm-initiated corruption (i.e., irregular payment and bribes offered to public officials as well as other firms) may produce fruitful results in both understanding and combating private corruption in these countries. Such research may provide valuable insights to the work of other researchers who have been studying private corruption (e.g., Argandona 2003, 2005; Fleming and Zyglidopoulos 2008; Gopinath 2007; Luo 2004). Similarly, since IPP appears as the leading factor affecting managers' perception of business ethics in Stage 1 countries, particular attention may be paid to the study of underlying structural factors affecting managers' perceptions of IPP in these countries. This research identified JI as the critical factor affecting IPP perceptions. In addition, the discussion section provided information regarding cultural underpinnings of IPP perceptions in many of the Stage 1 countries. Future research may look into other structural (e.g., political, natural, and competitive) factors affecting IPP perceptions in these countries. Furthermore, our analysis was based on the 92 states comprising the Stage 1, 2, and 3 countries of the WEF data. Future research can test the model on the "transition countries" which were excluded in the current study. Future studies may also investigate how perceptions of managers change over time regarding the business ethics system in the countries where they work.

Finally, in order to reduce the extent of subjectivity which is inherit in the expert panel method, as a further study, a Bayesian net can be developed through structural learning from data. By this way, qualitative relationships between variables can be captured solely depending on Bayes' probabilities of the variables. The comparison of the two models (one constructed from data and one based on the views of experts) can potentially lead to more interesting results about the EBOF.

\section{Appendix}

The list of 20 variables (concepts) comprising the "Institutions Pillar" of the GCI

1.01 Property rights

1.02 intellectual property protection

1.03 Diversion of public funds

1.04 Public trust of politicians

1.05 Irregular payments and bribes

1.06 Judicial independence

1.07 Favoritism in decisions of government officials

1.08 Wastefulness of government spending

1.09 Burden of government regulation

1.10 Efficiency of legal framework in settling disputes

1.11 Efficiency of legal framework in challenging regulations

1.12 Transparency of government policymaking

1.13 Business costs of terrorism

1.14 Business costs of crime and violence

1.15 Organized crime

1.16 Reliability of police services

1.17 Strength of auditing and reporting standards

1.18 Efficacy of corporate boards

1.19 Protection of minority shareholders' interests

1.20 Strength of investor protection

\section{References}

Akaah, I. P. (1989). Differences in research ethics judgments between male and female marketing professionals. Journal of Business Ethics, 8, 375-381.

Aktas, E., Ulengin, F., \& Onsel, S. (2005). A decision support system to improve the efficiency of resource allocation in health care management. Socio-Economic Planning Sciences, 41(2), $130-146$.

Argandona, A. (2003). Private-to-private corruption. Journal of Business Ethics, 47, 253-267.

Argandona, A. (2005). Corruption and companies: The use of facilitating payments. Journal of Business Ethics, 60, 251-264.

Barnett, T., Bass, K., \& Brown, G. (1994). Ethical ideology and ethical judgment regarding ethical issues in business. Journal of Business Ethics, 13, 469-480.

Batten, J., Hettihewa, S., \& Mellor, R. (1999). Factors affecting ethical management: Comparing a developed and developing economy. Journal of Business Ethics, 19(1), 51-59.

Blundo, G., \& Olivier de Sardan, J. P. (2006). Everyday corruption and the state. Citizens and public officials in Africa. London: Zed Books.

Bommer, M., Gratto, C., Gravander, J., \& Tuttle, M. (1987). A behavioral model of ethical and unethical decision making. Journal of Business Ethics, 6, 265-280.

Britz, J. J., \& Lipinski, T. A. (2001). Indigenous knowledge: A moral reflection on current legal concepts of intellectual property. Libri, 51, 234-246.

Burns, J. O., \& Kiecker, P. (1995). Tax practitioner ethics: An empirical investigation of organizational consequences. Journal of the American Taxation Association, 17(2), 20-49. 
Chabal, P., \& Daloz, J-P. (1999). Africa works: Disorder as political instrument. Indiana University Press.

Cleek, M. A., \& Leonard, S. L. (1998). Can corporate codes of ethics influence behavior. Journal of Business Ethics, 17, 619-630.

Donoho, C. L., Polonsky, M. J., Herche, J., \& Swenson, M. J. (1999). A cross cultural examination of the general theory of marketing ethics: Does it apply to the next generation of marketing managers? In S. Smith (Ed.), Proceedings of the Seventh Cross Cultural Research Conference, Cancun, Mexico.

Dornoff, R. J., \& Tankersley, C. B. (1975). Do retailers practice social responsibility? Journal of Retailing, 51(4), 33-42.

Eden, C., \& Ackermann, F. (1998). Making strategy. London: Sage Publications.

Fenton, N., \& Neil, M. (2000). Making decisions: Using Bayesian nets and MCDA. Knowledge-Based Systems, 14(7), 307-325.

Ferrell, O. C., \& Gresham, L. G. (1985). A contingency framework for understanding ethical decision making in marketing. Journal of Marketing, 49(Summer), 87-96.

Fleming, P., \& Zyglidopoulos, S. C. (2008). The escalation of deception in organizations. Journal of Business Ethics, 81, $837-850$

Ford, R. C., \& Richardson, W. D. (1994). Ethical decision making: A review of the empirical literature. Journal of Business Ethics, 13, 205-221.

Giacalone, R. A., \& Jurkiewicz, C. L. (2003). Right from wrong: The influence of spirituality on percetions of unethical business activities. Journal of Business Ethics, 46, 85-97.

Gopinath, C. (2007). Recognizing and justifying private corruption. Journal of Business Ethics, 82, 747-754.

Hegarty, W. H., \& Sims, H. P, Jr. (1978). Some determinants of unethical decision behavior: An experiment. Journal of Applied Psychology, 63(4), 451-457.

Hunt, S. D., \& Vasquez-Parraga, A. (1993). Organizational consequences, marketing ethics and salesforce supervision. Journal of Marketing Research, 30(February), 78-90.

Hunt, S. D., \& Vitell, S. M. (1986). A general theory of marketing ethics. Journal of Macromarketing, 6(Spring), 5-15.

Hunt, S. D., \& Vitell, S. M. (1993). The general theory of marketing ethics: A retrospective and revision. In N. C. Smith \& J. A. Quelch (Eds.), Ethics in marketing (pp. 775-784). Homewood, IL: Irwin.

Hunt, S. D., \& Vitell, S. M. (2006). The general theory of marketing ethics: A revision and three questions. Journal of Macromarketing, 26(2), 143-153.

Jensen, F. (2002). Bayesian networks and decision graphs. New York: Springer.

Jing, R., \& Graham, J. L. (2008). Values versus regulations: How culture plays its role. Journal of Business Ethics, 80, 791-806.

Jones, T. M. (1991). Ethical decision making by individuals in organizations: An issue-contingent model. Academy of Management Review, 16(2), 366-395.

Kameri-Mbote, P. (2005). Towards greater access to justice in environmental disputes in Kenya: Opportunities for intervention. International Environmental Law Research Center.

Kemmerer, B., \& Shenoy, P. (2007). Bayesian causal maps as decision aids in venture capital decision making: Methods and applications. http://citeseerx.ist.psu.edu/viewdoc/summary?doi= 10.1.1.16.7947.

Lam, K-C., \& Shi, G. (2008). Factors affecting ethical attitudes in mainland China and Hong Kong. Journal of Business Ethics, 77, 463-479.

Lere, J. C., \& Gaumnitz, B. R. (2003). The impact of codes of ethics on decision making: Some insights from information economics. Journal of Business Ethics, 48, 365-379.
Loe, T. W., Ferrell, L., \& Mansfield, P. (2000). A review of empirical studies assessing ethical decision making in business. Journal of Business Ethics, 25, 185-204.

Luo, Y. (2004). An organizational perspective of corruption. Management and Organization Review, 1(1), 119-154.

Mayo, M. A., \& Marks, L. J. (1990). An empirical investigation of a general theory of marketing ethics. Journal of the Academy of Marketing Science, 18(Spring), 163-172.

McCabe, A. C., Ingram, R., \& Dato-on, M. C. (2006). The business of ethics and gender. Journal of Business Ethics, 64, 101-116.

McKinney, J. A., \& Moore, C. W. (2008). International bribery: Does a written code of ethics make a difference in perceptions of business professionals. Journal of Business Ethics, 79, 103-111.

Menguc, B. (1998). Organizational consequences, marketing ethics, and salesforce supervision: Further empirical evidence. Journal of Business Ethics, 17(4), 333-352.

Mishra, S., Kemmerer, B., \& Shenoy P. (2001). Managing venture capital investment decisions: A knowledge-based approach. Working Paper, School of Business, University of Kansas.

Mitchell, T. R., Daniels, D., Hopper, H., George-Falvy, J., \& Ferris, G. R. (1996). Perceived correlates of illegal behavior in organizations. Journal of Business Ethics, 15, 439-455.

Nadkarni, S., \& Shenoy, P. (2001). A Bayesian network approach to making inferences in causal maps. European Journal of Operational Research, 128, 479-498.

Nadkarni, S., \& Shenoy, P. (2004). A causal mapping approach to constructing Bayesian networks. Decision Support Systems, $38(2), 259-281$.

Nicholson, A., Twardy, C. R., Korb, K. B., \& Hope, L. R. (2008). Decision support for clinical cardiovascular risk assessment. In O. Pourret, P. Naim, \& B. Marcot (Eds.), Bayesian networks: A practical guide to applications bayesian networks (pp. 33-52). Cornwall: Wiley.

Nill, A., \& Schibrowsky, J. A. (2007). Research on marketing ethics: A systematic review of literature. Journal of Macromarketing, 27(3), 256-273.

O'Fallan, M. J., \& Butterfield, K. D. (2005). A review of the empirical ethical decision-making literature: 1996-2003. Journal of Business Ethics, 59, 375-413.

Onsel-Sahin, S., Ülengin, F., \& Ülengin, B. (2006). A Bayesian causal map for a dynamic inflation analysis: The case of Turkey. European Journal of Operational Research, 175(2), 1268-1284.

Oz, E. (2001). Organizational commintment and ethical behavior: An empirical study of information system professionals. Journal of Business Ethics, 34(2), 137-142.

Pitta, D. A., Fung, H. G., \& Isberg, S. (1999). Ethical issues across cultures managing the differing perspectives of China and the USA. Journal of Consumer Marketing, 16(3), 240-256.

Prasad, J. N., \& Rao C. P. (1982). Foreign payoffs and international business ethics: Revisited. Southern Marketing Association Proceedings (pp. 260-264).

Roberston, D. C. (2009). Corporate social responsibility and different stages of economic development: Singapore Turkey, and Ethiopia. Journal of Business Ethics, 88, 617-633.

Roberston, D. C., \& Rymon, T. (2001). Purchasing agents deceptive behavior: A randomized response technique study. Business Ethics Quarterly, 11(3), 585-599.

Sala-i-Martin, X., Bilbao-Osorio, B., Blanke, J., Hanouz, M. D., Geiger, T. (2011). The Global Competitiveness Index 2011-2012: Setting the foundations for strong productivity. Global Competitiveness Report, 2011-2012.

Sala-i-Martin, X., Blanke, J., Hanouz, M. D., Geiger, T., \& Mia, I. (2010). The Global Competitiveness Index 2010-2011: Looking beyond the global economic crisis. Global Competitiveness Report, 2010-2011. 
Sikoyo, G. M., Nyukuri, E., \& Wakhungu, J. W. (2006). Intellectual property protection in Africa. African Centre for Technology Studies (ACTS), Ecopolicy Series; 16.

Sims, R. L., \& Gegez, A. E. (2004). Attitudes towards business ethics: A five nation comparative study. Journal of Business Ethics, 50, 253-265.

Singhapakdi, A., \& Vitell, S. J. (1990). Marketing ethics: Factors influencing perceptions of ethical problems and alternatives. Journal of Macromarketing, 10(Spring), 4-18.

Singhapakdi, A., \& Vitell, S. J. (1991). Research note: Selected factors influencing marketers. Deontological Norms', Journal of the Academy of Marketing Science, 19(Winter), 37-42.

Soutar, G., McNeil, M. M., \& Molster, C. (1994). The impact of the work environment on ethical decision making: Some australian evidence. Journal of Business Ethics, 13, 327-339.

Srnka, K. J. (2004). Culture's role in marketers' ethical decision making: A integrated theoretical framework. Academy of Marketing Science Review, 2004(1), 1-32.

Stajkovic, A. D., \& Luthans, F. (1997). Business ethics across cultures: A social coginitive model. Journal of World Business, 32(1), 17-34.

Stead, W. E., Worrell, D. L., \& Stead, J. G. (1990). An integrative model for understanding and managing ethical behavior in business organizations. Journal of Business Ethics, 9, 233-242.

Tranparency International. (2010). Corruption perceptions index. www.transparency.org.

Trevino, L. K. (1986). Ethical decision making in organizations: A person-situation interactionist model. Academy of Management Review, 11(3), 601-617.
Tsalikis, J., \& Fritzsche, D. J. (1989). Business ethics: A literature review with a focus on marketing ethics. Journal of Business Ethics, 8, 695-743.

Ülengin, F., Kabak, O., Onsel, S., Ulengin, B., \& Aktaş, E. (2010). A problem-structuring model for analyzing transportation-environment relations. European Journal of Operational Research, 200(3), 844-859.

Velasquez, M. (2010). Corruption and bribery. In G. G. Brenkert \& T. L. Beauchamp (Eds.), The Oxford handbook of business ethics. New York: Oxford University Press.

Vitell, S. J. (1986). Marketing ethics: Conceptual and empirical foundations of a positive theory of decision making in marketing situations having ethical content. Unpublished dissertation, Texas Tech University.

Vitell, S. J., Singhapakdi, A., \& Thomas, J. (2001). Consumer ethics: An application and empirical testing of the Hunt-Vitell theory of ethics. Journal of Consumer Marketing, 18(2), 153-178.

Winter, S. J., Stylianou, A. C., \& Giacalone, R. A. (2004). Individual differences in the acceptability of unethical information technology practices: The case of Machiavellianism and ethical ideology. Journal of Business Ethics, 54, 279-301.

Wyld, D. C., \& Jones, C. A. (1997). The importance of context: The ethical work climate construct and models of ethical decision making - an agenda for research. Journal of Business Ethics, 16, $465-472$. 